\title{
The Impact of Rent Controls in Non-Walrasian Markets: An Agent-Based Modeling Approach
}

by

Ralph Bradburd

Stephen Sheppard

Joseph Bergeron and

Eric Engler

Department of Economics

Fernald House

Williams College

Williamstown, MA 01267

\begin{abstract}
We use agent-based models to consider rent ceilings in non-Walrasian housing markets, where bargaining between landlord and tenant leads to exchange at a range of prices. In the non-Walrasian setting agents who would be extramarginal in the Walrasian setting frequently are successful in renting, and actually account for a significant share of the units rented. This has several implications. First, rent ceilings above the Walrasian equilibrium price (WEP) can affect the market outcome. Second, rent ceilings that reduce the number of units rented do not necessarily reduce total market surplus. Finally, the distributional impact of rent controls differs from the Walrasian setting.
\end{abstract}

JEL Classification: R31, R52, L51

*The authors may be reached by email at:

Stephen.C.Sheppard@williams.edu

or

Ralph.M.Bradburd@williams.edu 


\section{INTRODUCTION}

While disagreements amongst economists are legion, a study of consensus within the dismal science by Alston, Kearl and Vaughan (1992) identified many economic propositions about which there was considerable agreement. Of the forty propositions examined, the one that generated the greatest degree of agreement was the proposition that rent ceilings are bad ${ }^{1}$. Olsen (1998) elaborates, noting that the “... overwhelming majority of economists oppose rent control on the grounds that it creates major inefficiencies ... [and is] an extremely inequitable redistributive device.”

With the weight of this collective authority, one might have thought the issue was settled and there is little more to say about rent control policies. In recent years, however, there have been several papers that have yielded new insights concerning the effects of rent controls. Among these are analyses by Arnott (1995), Nagy (1995), Arnott and Igarashi (2000), Glaeser (1996), Munch and Svarer (2002), Glaeser and Luttmer (2003) and others cited therein.

Although their approaches are quite different from one another, each of these papers incorporates (at least implicitly) some element of random matching of landlords and tenants that occurs because prices are kept from playing their usual allocative function. The result is a sub-optimal equilibrium matching of tenants with rental housing units. These analyses provide a more complex but richer understanding of the impact of rent controls than is possible with "standard" textbook treatments of the topic. Despite incorporating elements of random matching, however, each of these papers retains a central feature of Walrasian markets: the law of one price. That is, they assume that all transactions occur at a single “market clearing” price, known to all participants, just as if there were a Walrasian auctioneer. In such a Walrasian market, absent government intervention, the efficient amount of the good is exchanged and total economic surplus within the market is maximized conditional on output because the market mechanism acts to exclude extramarginal traders, purchasers of the good whose valuation is lower than the market-clearing price and sellers whose supply price exceeds it. 
In contrast to these papers and the standard textbook analyses, we characterize the housing market in our model as non-Walrasian, in the sense that all trades do not occur at a single equilibrium price and extramarginal buyers or sellers are able to make trades. It should be noted that such a market is neither exotic nor difficult to comprehend. Most housing and rental markets exhibit features we would describe as non-Walrasian, for example essentially identical units trading for different prices so that there is a distribution of prices rather than a single equilibrium price. ${ }^{2}$ In part, this is because resale is prohibited or limited, so that buyers who manage to secure a unit at a low price cannot immediately resell to a buyer with a higher reservation price. Other reasons could include the existence of search costs or discounting. Although there are economic models in which non-Walrasian trading occurs, these are rarely if ever applied in the context of real-world government interventions in the functioning of markets, such as rent controls.

The recent paper by Glaeser and Luttmer (2003) provides a useful starting point for presenting our analysis because, while preserving the law of one price, it focuses attention on trades involving renters who would be extramarginal in the absence of rent control. ${ }^{3}$ Glaeser and Luttmer observe that most models of the impact of rent controls, and almost all textbook discussions, implicitly assume that the same forces that operate to ensure that total surplus is maximized in Walrasian competitive markets also operate when a price ceiling is imposed in such markets. That is, standard textbook analyses of the welfare loss from rent control assume that although there is a welfare loss from the reduction in housing supply that attends the imposition of rent controls (the "undersupply costs"), those units that continue to be offered for rental are allocated to those whose reservation prices for housing are highest. ${ }^{5}$ However, as they argue, once price is ruled out as the rationing device, all consumers whose reservation price exceeds the ceiling price are indistinguishable in the market and all should have an equal chance of obtaining the good. In this situation, rather than assuming that the price-controlled rental units go only to those with the highest reservation prices, it is more appropriate to assume that the rental units are allocated randomly among all consumers willing to pay the rent-controlled price or more. As a result, the 
average value of a rental unit to those who succeed in renting is equal to the average of the reservation prices of all consumers who would gain from exchange at the ceiling price. Here, there are reductions in total surplus as a result of displacement ${ }^{6}$ of inframarginal renters by extramarginal renters; these "misallocation" costs cause the total welfare loss from rent control potentially to be much larger than the standard textbook deadweight loss triangle.

This is illustrated in Figure 1. The total welfare loss from rent control when apartments are randomly allocated across all renters willing to pay the ceiling price is area DGE plus CBFD, the former constituting the standard welfare loss triangle due to undersupply and the latter the lost consumer surplus due to misallocation of the units supplied among the renters in the market at the ceiling price.

[Figure 1 about here]

In taking misallocation losses into account to create a more comprehensive measure of welfare loss, Glaeser and Luttmer compare the total surplus under rent controls with the level that would obtain in the Walrasian competitive equilibrium. In our analysis we use non-Walrasian equilibrium as the basis for comparisons of welfare with and without rent controls. We argue that the characteristics of the rental housing market are such that random processes play a role in allocation of rental units in both the priceconstrained and the unconstrained equilibrium. If there are "out-of-equilibrium" trades that occur in the unconstrained rental market, then these should be considered in determining the appropriate standard for measuring the welfare costs of rent controls.

One reason that economists have not fully addressed the complications raised by non-Walrasian trading in analyzing policy interventions such as rent controls is that it is exceedingly difficult to derive simple closed-form analytical solutions for equilibria in such markets, and even more difficult to do so in ways that incorporate distributional impacts. Nevertheless, the distributional impact of rent-control policies is clearly of great importance. In this paper, we employ agent-based modeling simulations to consider the partial equilibrium economic impact of rent controls in a non-Walrasian context, that is, in situations in which the law of one price does not hold and in which "out-of-equilibrium” trades can occur. 
Within this context we analyze the impact of rent controls on total economic surplus, on the distribution of total surplus between landlords and tenants, and on the distribution of surplus among tenants and among landlords.

Rent controls and similar interventions are frequently justified politically on the grounds that they will benefit the economically disadvantaged even though it is recognized that, except in the case of perfectly inelastic supply, there will be a welfare-reducing supply response. Our computational technique provides an alternative approach to analyzing the welfare and distributional effects of price controls in non-Walrasian market settings, including the possibility of taking into account the extent to which lowreservation price consumers might be participating in the market even in the absence of rent controls. This alternative approach leads to some surprising conclusions. Specifically, in our model, rent ceilings that would be non-binding in a Walrasian setting will change the market outcome and, at least under some conditions, will increase total welfare. Further, under a variety of assumptions regarding renters' and landlords' reservation prices, rent ceilings in our model provide little or no benefit to low-reservationprice renters in the absence of inordinately large sacrifices in total surplus, weakening the political case for implementing rent-control policies.

Section II below provides a general introduction to our agent-based simulation model. Section III describes our results, while Section IV considers their policy implications. Section V concludes and discusses possible extensions of our model.

\section{AN AGENT-BASED MODEL OF RENTAL HOUSING}

Agent based modeling is analysis of complex systems through simulations that are based on specification of the behavior of individual agents who interact, within some structured space of possible choices, over "time" consisting of rounds of interaction or cycles in the computer running the simulation. Unlike most simulation exercises with which economists and regional scientists may be 
familiar, agent based modeling does not specify structural equations for the entire market. The analysis proceeds instead through specification of relatively simple behavioral rules for each agent, along with the structure of the space within which they interact. The outcome of the exercise is a sequence of decisions that can be summarized and analyzed using the same techniques used for empirical analysis of micro data. Thus an agent based model is a "data generating process" (to borrow from econometric jargon) where the analyst has control over features of the process, and can investigate how changing these features will affect the data that emerge. In this way, agent-based modeling permits formation of testable hypotheses about the likely impacts of comparable changes in actual markets or systems.

We employ computer-simulated decision-makers, or 'agents,' to model the impact of rent controls in a non-Walrasian environment. Each agent has a well-defined objective, constraints within which it must operate, including but not limited to informational constraints, and well-defined rules for interaction with other agents within the simulated environment. The particular model we employ assumes two classes of economic agents, renters and landlords, with $m$ renters and $n$ landlords. Each renter rents at most one discrete "unit" of housing, and each is characterized by a reservation price, defined as the price above which the renter receives zero net utility from a rental transaction. Each landlord agent has one housing unit to rent, and each is characterized by its reservation price for that unit, which we assume to be that landlord's marginal cost of providing the unit. All units of housing are identical; the differences in landlords' marginal costs derive from differences in their costs of keeping their rental unit in the residential housing market. ${ }^{7}$ Renters derive utility from a composite good and housing and have a separable utility function in which housing enters linearly. Landlords derive utility from a composite good and seek to maximize the difference between the rental price and marginal cost. Markets 'play out' over a sequence of trades, and agents care only about the surplus they obtain from a trade (if any) during the market period. ${ }^{8}$ To simplify the analysis, we further assume that there are no search costs or negotiation costs. 
Agents encounter each other randomly and may be thought of as engaging in a game of alternating offers that either concludes with a transaction at a price determined by the Nash bargaining solution, or a separation if either agent expects to receive greater surplus from a future encounter. Consider the renterlandlord matching process in the context of simulating in a market of $m$ renters and $n$ landlords. ${ }^{9}$ Within a market simulator run, renters and landlords in the market are sequentially ${ }^{10}$ drawn at random from separate pools to participate in bargaining encounters; if both agents find it desirable to exchange, determined by conditions described below, the transaction is recorded and they are removed from their respective pools without replacement. If not, they are returned to their respective pools. There is no “recall” of bargaining opportunities, in the sense that bargaining opportunities can not be "reserved" while an agent engages in further search. Renters and landlords continue to be drawn at random until the market run is completed, which occurs when all exchange possibilities among the $m$ renters and $n$ landlords in the market are exhausted. ${ }^{11}$ We store for subsequent analysis the outcome of each renterlandlord bargaining encounter within the market run.

The particular order in which the agents happen to be selected in the random matching process can affect all aspects of the outcome of a market run, including total surplus, the number of completed bargains, and the distribution of surplus among the agents. To avoid the possibility of basing our analyses on an "outlier" market run and to ensure that events that occur with lower frequency are adequately represented, we define simulation "results" for each variable of interest to be the observed average value over 20,000 market simulator runs.

We assume that when a renter and landlord are drawn from their respective pools, they engage in a bargaining process based on a Rubinstein alternating offers game ${ }^{12}$ to determine a price for the rental unit. Under standard assumptions, the Nash bargaining solution is the unique subgame-perfect equilibrium for such a game. Each renter (landlord) has a reservation price as described above and also an expected surplus from future bargaining opportunities, the latter determining the renter's (landlord's) disagreement point. In the unconstrained bargaining case an encounter between a tenant and landlord 
will result in a rental price that gives both agents the same gain relative to their respective disagreement points, specified by:

$$
P_{i, j}=\frac{\left(P_{R_{i}}-R E B_{i}+P_{L_{j}}+L E B_{j}\right)}{2}
$$

where

$P_{i, j}=$ the unconstrained price obtained in an exchange between renter $i$ and landlord $j$;

$P_{R_{i}}=$ the reservation price of the $\mathrm{i}^{\text {th }}$ renter;

$R E B_{i}=$ the $\mathrm{i}^{\text {th }}$ renter's expected surplus in the market if she rejects the current trade; ${ }^{13}$

$P_{L_{j}}=$ the reservation price (= marginal cost) of the $\mathrm{j}^{\text {th }}$ landlord

$L E B_{j}=$ the $\mathrm{j}^{\text {th }}$ landlord's expected surplus in the market if he rejects the current trade;

In the cases where a ceiling on rent is imposed, the price that obtains in any bargaining encounter is

$$
\mathrm{P}^{*}=\min \left(P_{i j}, P_{C}\right) \text {, where } P_{C} \text { is the rental price ceiling. }{ }^{14}
$$

Clearly, there can be no exchange between a renter and a landlord if the landlord's reservation price (marginal cost) for a rental unit exceeds that of the renter, nor will a bargain be possible if the landlord's reservation price exceeds the rental price ceiling. Further, as equation (1) implies, there can be no bargain if the difference between the agents' reservation prices is exceeded by the sum of the renter's and landlord's expected surplus in the event that she (he) rejects the current trade.

The bargaining model described by equation (1) is quite standard; the challenge is in finding a reasonable approach for determining the agents' respective disagreement points. The appropriate disagreement point for each agent in our environment is the expected value of the surplus the agent would receive if she (he) rejected the current bargaining opportunity. If we expand to the limit the information 
available to agents and their ability to process it, such expected surplus would in principle be a function of the numbers and reservation prices of all opposite-type and same-type agents remaining in the market, of the nature of the bargaining process that determines prices in bargaining encounters, and of possibilities for strategic bargaining strategies. Attempting to take all these factors into account is analytically intractable and computationally impractical, however; further, it requires us to assume that agents have both analytical abilities and information that strain credulity. Our analysis takes a more parsimonious approach that relies on a two-stage simulation process to generate disagreement points for agents that are derived from simulated experience.

In the first, or "bootstrap" stage, agents acquire knowledge that they then employ in their bargaining encounters in the second stage, the outcomes of which provide our simulation results. Ideally, the knowledge that agents possess when they engage in bargaining in the second-stage should simulate the information available to traders in actual rental housing markets, and be neither unreasonably extensive nor limited. The knowledge that agents acquire in the first stage simulations should provide them with some reasonable guidance as to their optimal bargaining stance in the second stage simulations, but should not be so comprehensive as to approach perfect information because that would be unrealistic in our context. We assume that a renter drawn for a bargaining encounter within a second-stage market run knows, first, how many transactions have already occurred in the market run at the point she is drawn, which we call the "transaction count," and second, knows how much surplus a renter with her reservation price can expect to receive in the market when she rejects a feasible bargain at that particular transaction count. ${ }^{15}$ Each landlord has equivalent information. ${ }^{16}$ It is this knowledge that informs the agents' respective disagreement points in the second-stage simulations when they engage in the bargaining process summarized by equation (1).

In the bootstrap stage we assume that each agent begins the learning process with the naïve belief that the alternative to accepting a feasible bargain is to receive no surplus at all. This leads them to accept any proposed feasible trade ${ }^{17}$. During the bootstrap round, feasible trades are allowed to proceed with 
probability $1 / 2 .{ }^{18}$ For those exchanges randomly selected for cancellation, each agent notes the number of transactions that had occurred, and keeps track of the level of surplus eventually attained in that market. These experiences are averaged over all iterations in the bootstrap stage, and provide values for the disagreement points in subsequent stages. We want all agents to have sufficient "experience" in the bootstrap stage to ensure that each agent's expected surplus conditional on rejecting a feasible trade at each particular transaction count is robust in the sense of not being an "outlier" outcome. ${ }^{19}$

Renters or landlords with different reservation prices will naturally have different experiences in the bootstrap stage. Furthermore, an agent's expected surplus after rejecting a feasible trade will vary with the transaction count within the bootstrap stage. At any given transaction count, agents who are more favorably situated in the market (renters with high reservation prices and landlords with low reservation prices) are much more likely to be matched with an opposite type agent with whom a bargain is feasible than are less favorably situated agents; thus, their expected surplus conditional on rejecting a feasible trade at that transaction count will be higher. At the same time, because more favorably situated agents are withdrawn from the pools from which agents are selected in the matching process when they complete a bargain, the pools of renters and landlords from which agents are drawn becomes more and more dominated by low reservation price renters and high reservation price landlords over the course of a market run. The result is that for the typical agent, the expected surplus received after rejecting a feasible bargain falls as the transaction count increases. Thus, the agents' disagreement points in their bargaining encounters in the second-stage simulations, which are derived from bootstrap stage experience, will vary both as a function of their reservation prices and the transaction count.

Taking the bootstrap-stage results as a robust prediction of an agent's likely surplus within a market run if (s)he rejects a proposed trade at a particular transaction count, they provide sensible disagreement points for agents in bargaining encounters in the second stage of our iterative process, the stage that generates results for analysis. During the second stage randomly matched tenants and landlords consider proposed exchanges at prices determined by equation (1), with disagreement points for each 
based on the bootstrap stage. All trades that generate for each agent a surplus that is at least equal to the surplus to be expected from rejecting the trade at that point in the market will take place, and the market proceeds until no further trades are possible. As was true for the bootstrap stage, to avoid obtaining results that might differ from the "expected outcome" simply because of the nature of the random process of selecting agents for bargains, our reported second stage results are also averages calculated over at least 20,000 market simulation runs. ${ }^{20}$

A possible objection to our approach is that the model assumes that every landlord has a vacant unit to rent. Rent controls are most frequently (though not universally) applied in housing markets where demand pressures could be expected to force rents higher, so that there are few vacancies in the market. Does this mean that our analysis only applies to rent control scenarios that never arise?

There are several reasons to reject this objection. First, even for rent controlled housing the turnover rates are not zero. While the evidence is somewhat mixed, it seems reasonable to expect that turnover rates in rent controlled housing units will be lower than in uncontrolled units. Munch and Svarer (2002) provide the strongest indication of reduced mobility due to rent controls, estimating that in Denmark the most restrictive controls increase the expected duration of residency by roughly 50 percent. If this applies in the US context, then we might expect roughly 10 percent of rent controlled housing units to be vacated and available for bargaining between landlord and renter each year. Our analysis would then apply to those properties, and should be taken as an indication of the distributional and price outcome towards which the housing market will converge over time.

A second rationale for accepting our model is that even when a household does not vacate their present rented unit and search for another one, there is scope for bargaining over terms of lease renewal, typically on an annual basis. These interactions present the landlord with the opportunity to increase the rent (subject, as in our model, to the constraint of the rent ceiling). They also offer the tenant the opportunity to threaten to leave and search for a new unit, which presumably she will do if her experience leads her to believe (as in our model) that her expected surplus will be greater if she submits herself to the 
random process of searching for new housing. This, combined with the first argument, would suggest that bargaining processes such as that modeled here are at work on a potentially large share of the rent controlled housing stock.

Clearly the analysis is based on a model, and acceptance of the model should be at most provisional while empirical tests of the observational implications of the model are carried out. There seems little reason, however, for a priori rejection of the analysis because not all units in a housing market are vacant. Indeed, such a perspective would imply rejection of essentially all existing models of the housing market, and certainly any competitive model of a housing market in which recontracting is assumed to occur until excess demand for housing units is zero.

\section{SIMULATION RESULTS}

We present the results of two simulation exercises. Both have the same demand structure: a single renter at each reservation price, approximating a linear market demand. For the supply of housing, we focus on a 'base case' scenario with one landlord at each reservation price, approximating a linear market supply whose price elasticity is equal to 1 . We compare this with an “inelastic supply” simulation.

\section{Base Case Results}

In our base-case simulation there are eleven renters and eleven landlords in the market, with reservation prices uniformly distributed, providing one tenant and one landlord with reservation prices

equal to each integer value from one to eleven, inclusive. ${ }^{21}$ The distribution of reservation prices in our model provides for an elastic market demand and supply even though each renter and landlord only rents or provides one housing unit. Our welfare analysis, and potentially the strategic options available to each 
agent, would require modification for application to situations where tenants or landlords bought and sold multiple units.

A tenant's reservation price is independent of the landlord with whom she is negotiating. It is reasonable to think of the variation in tenant's reservation prices as deriving from the variation in their income, with the housing units themselves being regarded as identical (or at least equally preferred). The variation across landlords in the reservation price or "marginal cost" would then derive from the unit's location and general landlord operating efficiency rather than the costs of adding an additional unit to a given structure.

In this non-Walrasian housing market, inefficiencies might arise due to three factors:

- restrictions in units supplied so that a house is not rented even though its owner's reservation price is below that of a potential tenant who remains without accommodation;

- misallocation of extramarginal tenants - with a tenant having a 'low' reservation price securing a low-cost house that would optimally have been allocated to a tenant with a higher reservation price;

- misallocation of extramarginal landlords - with a high cost housing unit allocated to a tenant with relatively high reservation price who would optimally have been allocated to a lower-cost house.

The first of these is the textbook source of inefficiency from rent control. The second of these is the focus of concern in Glaeser and Luttmer (2001). The third has not been fully explored in the literature, but can certainly arise in the presence of search costs. ${ }^{22} \mathrm{~A}$ novel feature of the model we explore is that such misallocation costs can arise even without explicit search costs, ${ }^{23}$ but simply because of the random process of matching landlords and tenants.

What features characterize the observed outcome in the absence of any rental price control? Two seem especially worthy of note: first, the total $^{24}$ number of trades exceeds that corresponding to the Walrasian competitive equilibrium, implying that there are "extramarginal” renters and landlords who 
succeed in concluding successful bargains; and second, the total surplus realized is less than that of the Walrasian case.

In the standard Walrasian market case that corresponds to our model (eleven agents on each side with reservation prices 1 to 11 inclusive) there will be six trades that occur in the market, all at a price of 6. In our non-Walrasian market, in contrast, the average value of the total number of trades is 6.43 , or roughly $7.1 \%$ more than in the Walrasian case. This might seem a surprising result: why should the introduction of some imperfections in the market increase rather than decrease the number of trades that occur? The answer lies in the fact that extramarginal traders succeed in making trades in the nonWalrasian world, whereas in the Walrasian world with recontracting, neither landlords with reservation prices above the market clearing price nor renters with reservation prices below that price would get to trade in equilibrium.

Table 1 shows the number of transactions between every pair of traders in the base-case with no rental ceiling. In this setting $13.5 \%$ of the completed bargains involve extramarginal renters and $13.6 \%$ involve extramarginal landlords. In the absence of a rent ceiling, every time an extramarginal renter gets to complete a transaction it increases the probability that an extramarginal landlord will do so.

\section{[Table 1 about here]}

This extramarginal trading occurs because renters and landlords, matched for a bargaining encounter with an extramarginal agent, may determine that they are better off accepting the price determined by equations (1) - (2) above than refusing the bargain in the hope of getting a better deal in a future encounter. ${ }^{25}$ The extent of successful extramarginal-agent bargains (indicated in Table 1 in bold type) is surprisingly high. Identifying agents by their reservation prices, renters 4 and 5 account for $4.7 \%$ and $7.8 \%$ of the completed bargains, respectively, while landlords 8 and 7 account for $4.6 \%$ and $7.8 \%$. None of these trades would occur in a Walrasian market. Even renter 3 manages to complete trades 
occasionally, accounting for nearly $1 \%$ of completed bargains. Landlord 9, with a marginal cost that is $50 \%$ greater than the Walrasian equilibrium price, accounts for $1.28 \%$ of the transactions.

The extent of trading by extramarginal agents is important. In non-Walrasian housing markets, the appropriate standard against which to measure the costs or benefits of rent controls for particular subgroups is not the Walrasian outcome but something different. Consider the total economic surplus generated in our simulated rental housing market. The Walrasian equilibrium surplus in the market would be 30. The average total surplus in the unconstrained non-Walrasian market is 26.98. Therefore it might be said that the Walrasian model 'overestimates' the level of surplus that is likely to be realized; in this case it predicts a surplus that is $11.2 \%$ too high.

Total surplus is lower in the non-Walrasian environment because each extramarginal trade that occurs lowers the total surplus in the market relative to the Walrasian outcome. To the extent that realworld rental housing markets are characterized by non-Walrasian outcomes, using an approximation of the Walrasian outcome as the standard against which to measure the efficiency costs of rent controls may bias estimates of the true costs of rent control.

\section{Rent Ceilings in the Non-Walrasian Setting}

Rent ceilings affect the market in several ways. The most obvious effect is that any landlord whose reservation price is above the rental price control will be unable to complete any trades. Because there may be extra-marginal trades in the non-Walrasian setting, rent ceilings that are above the Walrasian equilibrium price may affect the market outcome. Thus, in the non-Walrasian setting we see the phenomenon of “ineffective” price constraints being effective. ${ }^{26}$

Table 2 shows how the volume of rentals relates to the level of the rental price ceiling. In general, reductions in the rent ceiling price result in decreased reduce rental volume even when the ceiling price is well above the Walrasian equilibrium price (henceforth we will abbreviate this phrase to WEP when 
convenient). The volume of rentals in the non-Walrasian case exceeds the volume in the Walrasian setting for all ceiling prices above the WEP; the volume of rentals is the same in both types of market for price ceilings below that level.

[Table 2 about here]

While price ceilings exert an obvious direct impact on the negotiated price in any bargaining encounter, there are indirect effects as well, ${ }^{27}$ which occur because price ceilings alter the disagreement points of renters and landlords. These changes may in turn alter the relative bargaining strengths of tenants and landlords. The existence of the price ceiling may lower the price that a renter can expect to pay, or landlord expects to receive, in any future successful bargaining interaction. This raises the renter's expected surplus from future bargains and lowers that of the landlord, shifting some bargaining power to the renter in any renter-landlord interaction. However, the fact that the "supply effect" of a rent ceiling diminishes the quantity of offered rental units means that a given renter (landlord) may face a diminished (greater) chance of being “drawn” for a feasible bargaining encounter. This tends to lower (raise) the renter's (landlord's) expected benefit from future bargains, ${ }^{28}$ the partial impact of which is to weaken the bargaining power of renters relative to landlords.

Figure 2 shows the impact of price ceilings on the average market price in our non-Walrasian setting. As discussed above, 'ineffective' price constraints do affect the average price in the nonWalrasian setting. Note that for rent ceilings below the WEP, the mean price is always lower in the nonWalrasian setting than in the Walrasian setting (where it equals the ceiling price), while the number of realized bargains is the same.

[Figure 2 about here]

An additional indirect effect of a rent ceiling is to change the degree to which landlords differentiate between lower-reservation price renters and higher-reservation price renters as desirable bargaining 
partners. With lower price ceilings, a landlord has less incentive to refuse a bargain with a lowreservation price renter in hopes of being matched with a high reservation price renter because the price ceiling reduces the difference in the bargaining price outcomes. This tendency to 'equalize' the chance of market participation for all renters whose reservation price exceeds the ceiling will potentially affect the distributional impact of the policies.

[Table 3 about here]

Table 3 shows the number and percentage of rentals accounted for by each renter type (rows) at each rent ceiling (columns). Note that as the ceiling is lowered from 10 to 9 to 8 , the share of rentals accounted for by the renters with the highest reservation prices increases and remains higher than in the unconstrained case. As the ceiling is reduced below the WEP, the "equalizing effect" comes to dominate and the share of rentals becomes more equal across renters. This effect is clearly illustrated in Figure 3, which presents the data from Table 3 in graphical form. The "equalizing effect” eventually increases the share of units going to each of the lowest reservation price renters.

[Figure 3 about here]

The impacts of ceilings on total surplus in the rental housing market and its distribution between renters and landlords in our simulations are also noteworthy. Figure 4 shows, for each integer price ceiling, the total surplus in the standard textbook analysis of the effects of rent control, the total surplus in a Glaeser-Luttmer setting (in which there are costs due to misallocation of rental units among consumers but no misallocation costs on the landlord side), and the total surplus in our non-Walrasian setting.

[Figure 4 about here] 
Comparing first the standard textbook analysis and the Glaeser-Luttmer analysis, we see that rental price ceilings above the WEP of 6 have no impact and that total surplus is the maximum possible in the market. For price ceilings below the equilibrium price the welfare losses are greater in the GlaeserLuttmer setting because of the misallocation of tenants to rental units, a central feature of their analysis.

In our base-case non-Walrasian setting, we see total surplus, which in the absence of a price ceiling is about $10 \%$ lower than in the Walrasian equilibrium, actually rising as the ceiling is progressively reduced to levels below 11, peaking at a rent ceiling of 8 and then falling as the ceiling is further reduced. ${ }^{29}$ This surprising result is not the result of the small number of renters and landlords in our agent-based model, but results from the nature of the market itself. Further evidence and discussion of this is presented in an appendix below.

Thus, in the non-Walrasian setting, the analysis of rent controls must be more nuanced than in the simple Walrasian or Glaeser-Luttmer world. In all three models, severely restrictive rent controls result in significant losses in total surplus. The non-Walrasian world, however, presents the possibility of rent ceilings that improve welfare because such ceilings reduce the extent of extramarginal trades. (The gain in total surplus in our base-case simulations occurred with a price ceiling of 8 was about $4 \%$ above that of the unconstrained market.)

The magnitude of any welfare increase depends on the balance between two impacts of price controls. On the one hand, price ceilings reduce the total number of units made available for rental in the market, which we would expect to reduce total surplus; on the other hand, price ceilings reduce the extent of welfare-reducing transactions by extramarginal traders, and this tends to increase total surplus. The impact of rent ceilings on extramarginal trades is shown in Figure 5, which gives the extent of trading by extramarginal renters and landlords. ${ }^{30}$ The impact of reduced extramarginal trade dominates when the price ceiling is somewhat, but not too much, above the Walrasian equilibrium price; the impact of reduced supply dominates for price ceilings below that equilibrium price. $^{31}$ 
[Figure 5 about here]

Naturally, rent ceilings have differing impacts on tenants and landlords, and it is useful to decompose the total surplus between these two groups. We show this in Figure 6. Our simulation results show that at price ceiling levels between 11 and 8, the gains in renter surplus outweigh the losses in landlord surplus, leading to an increase in total surplus. At price ceilings 7 and 6 , we observe modest declines in total surplus because the gains in renter surplus are not quite large enough to offset the declines in landlord surplus. Renter surplus begins to decline with the ceiling price when the ceiling price is reduced below the WEP, and actually falls below the level achieved with no constraint when the ceiling is set below $4 .{ }^{32}$

[Figure 6 about here]

\section{Distributional Impact of Rent Controls}

Rent controls are sometimes justified on the basis of preserving an equitable division of surplus between renters and landlords. This was the case in some cities in the period immediately following the second World War (Arnott, 1995, p. 100), but more often they are justified on the grounds that they will benefit those in the lower end of the income distribution (Gyourko and Linneman, 1989). If we make the assumption that, all else equal, renters with lower incomes have lower reservation prices for a rental unit than renters with higher incomes ${ }^{33}$, allowing us to equate the lowest reservation price renters with the poorest renters, then our base-case simulation results provide at best modest support for rent controls as a redistributional policy to aid low income households. 
In Figure 7 and Table 4 below we show the Gini coefficient for distribution of renter’s surplus at each price ceiling. These provide a measure of the inequality with which the average surplus is distributed across all renters.

[Figure 7 about here] [Table 4 here, adjacent to Figure 7]

In welfare analysis of rent controls we are confronted with the dilemma of defining the population whose welfare is of concern. On the one hand, we may be concerned with the entire set of potential residents, including those who fail to find accommodation and receive zero surplus. Alternatively, we may focus on the set of actual residents, considering the distribution of surplus among those who find accommodation and actually reside in the subject area, ignoring those who reside elsewhere (and receive some unknown amount of surplus residing in a different community). We calculate the Gini coefficients for both approaches, labeling the Gini that includes those who fail to trade Gini ${ }_{0}$, and the calculation that excludes those who fail to trade as Gini 1 . Whichever measure is used, a relatively severe price constraint is required to reduce the Gini coefficient for renter surplus below the level that occurs in the

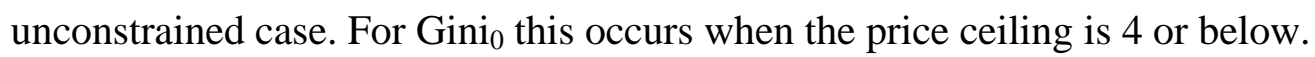

Of course, Gini coefficients might not tell the whole story; imposition of rent ceilings might substantially benefit the low reservation-price renters, whom we equate by assumption with lower-income renters, but just not as much as they benefit those with higher reservation prices. Our base-case simulation results do not provide strong support for this position.

Our simulation results suggest that rent controls may be relatively ineffective at transferring surplus to the poorest members of society. Table 5 below provides the expected change in renter surplus relative to the reservation price, compared to the unconstrained outcome, for each renter type at every rent ceiling between ten and one. The expected changes in surplus take into account the reduction in supply caused by the rent ceiling itself. 
[Table 5 about here]

The renter with reservation price 2 does not gain relative to the unconstrained outcome unless the ceiling price is set equal to 3 or lower, and at a rent ceiling of 3 her expected gain is less than 1 percent of her reservation price for housing, which is not a major gain. Expanding our focus to other renters with low reservation prices, we see that renter types 3 through 5 experience losses or very minimal changes in surplus at rent ceilings above 5. At a rent ceiling of 5, the lowest-income renters receive an increased surplus of $1.07 \%$ or less of their respective reservation prices for housing. Affluent renters gain considerably more. It is possible to achieve more significant gains for renter types 3,4 and 5 by setting a rent ceiling of three or two, but these gains come at the cost of significant sacrifice of total surplus.

A rental price ceiling of 5 is the highest price ceiling level that leaves the poorest five renter categories better off as a group in our base-case simulations. Here, the loss in total surplus is obviously much smaller than with a price ceiling of 3 , but even so, to produce this expected gain in surplus for the poor, the market must suffer an efficiency loss of about $13.7 \%^{34}$. (A rent ceiling of 4 provides greater gains to low income renters and positive gains for all renters, but at an even large market efficiency cost of $28.9 \%$.) It is possible to set rental price ceilings that lead to gains in overall renter surplus at no sacrifice of total surplus at all; however, as is evident in Table 5, at these price ceilings, all of which are above the WEP, it is only the high reservation price renters types who realize non-trivial gains.

The distributional impact of rental price ceilings that we find in our simple non-Walrasian model is consistent with the results of an empirical study of rent controls in New York City by Gyourko and Linneman (1989). They found that access to rent controlled units is not well targeted on the basis of family income and further, that within the group of tenants who do live in rent-controlled units, the rent subsidy benefit is not well targeted on the basis of income. They concluded that the New York City's rent control laws may have increased both horizontal and vertical inequality among controlled renters and 
that "if the primary social benefits of rent controls are their distributional impacts, they were not successful in New York." Our model may help explain some of the forces that produce the regressive distributional impact of rent controls in their study.

Two broad factors determine how well a given renter-type (identified by reservation price) fares under any given price ceiling regime and therefore who gains and who loses from imposition of rent controls: first, the renter's chance of concluding a successful bargain with a landlord; and second, whether the bargain will be concluded on terms more or less favorable to the renter. These in turn depend upon the combined impact of the previously discussed "supply effect” and "equalizing effect," as well as what we will call the "bargaining strength effect,” and the "direct price ceiling effect."

Consider the impact on two renters, say renter 4 and renter 8, of a lowering of the price ceiling from 7 to 6 . One implication of cutting the ceiling price is to reduce by one the number of landlords willing to rent a unit, which has the partial effect of reducing the probability that either renter will succeed in renting. This is the "supply effect" of lowering the price ceiling. Note that the effect is greater for renter 8 because renter 8 could actually have concluded a bargain with landlord 7, who has now exited the market, while renter 4 could not. ${ }^{35}$

At the same time, cutting the ceiling from 7 to 6 means that the gap between renter 4's reservation price and the greatest amount that a landlord can hope to receive from a bargain with renters 7 through 11 is now smaller, which has the partial effect of making renter 4 relatively less unattractive as a bargaining partner than is the case with the higher price ceiling. This is the "equalizing effect" of a drop in the price ceiling, which in general works in favor of lower reservation-price renters.

A reduced price ceiling will change both the renter's and the landlord's expected surplus from future bargaining encounters, thereby altering the terms at which a bargain between a particular renter and a particular landlord would be concluded, if it is concluded. This is the "bargaining strength effect." This impact will not be identical for all renters. On the renter's side, renter 4 sees a smaller change than renter 8 in the probability of concluding a successful match as a consequence of lowering the rental price ceiling 
from 7 to 6; however she experiences no reduction in the maximum price she would ever have to pay. In general, the two effects will not be exactly offsetting, and there will be a different impact on the two renters' respective expected benefit from future bargains, which implies a differential impact of the price ceiling on the negotiated price when they are in a bargaining interaction. A similar set of factors is at work in the case of landlords.

Finally we have the "direct price ceiling effect.” Assuming that a tenant has a chance to bargain with a landlord whose reservation price is below the price ceiling and that there is room for a mutually beneficial bargain (that is, the sum of the surplus available in the deal exceeds the sum of the renter's and landlord's expected benefits from future trade), the maximum rental price can be no higher than the price ceiling. All else equal, the greater the reservation price of the renter, the greater will be the gap between that reservation price and the price-ceiling-constrained negotiated rental. As the rental price ceiling is lowered, the partial impact of the "direct price ceiling effect" is to increase the share of renter surplus going to the highest reservation price renters.

With all of these factors operating with different strengths and interacting to affect the total surplus going to each renter type under each rental price ceiling, the distributional impact of rent controls will vary with the level of the ceiling. This helps to explain why in Table 5 above we see that price ceilings that are moderately above the WEP lead to big gains for the renters with the highest reservation prices and losses for those with low reservation prices, while price ceilings that are far below the WEP lead to gains for low reservation price renters and losses in surplus for those agents with the highest reservation prices.

\section{Inelastic Supply Case Simulations}

To this point, we have discussed only the results of our "base-case” non-Walrasian simulations in which there was unit elasticity of supply. Standard analyses of price controls show greater opportunity 
for raising buyer welfare at a low cost of total surplus (or none at all) when supply is inelastic, raising the possibility that our base-case simulations may be overly pessimistic regarding the prospects for using rental price ceilings as a redistributional mechanism. We therefore turn our attention now to simulations in which supply is perfectly inelastic. ${ }^{36}$ Perfectly inelastic supply is clearly an extreme assumption, and (at least for U.S. housing markets) is not supported by the empirical literature. Malpezzi and Maclennan (2001), for example, estimate (annual) flow elasticities for housing supply of between 6 and 13, and stock elasticities of between 1 and 6. These are roughly consistent with the simulations presented above.

On the other hand, the inelastic supply case may be relevant in the very short run, and in heavily regulated markets. We view the simulation results derived under this assumption as providing information on the limiting case, and the results may be instructive.

We employ the same two-stage simulation process as in our base-case simulations in which agents use their "experience" from the bootstrap stage to determine the disagreement points that inform their bargaining behavior in the second simulation stage. However, we change the market conditions in two important ways. Although we leave the distribution of renter reservation prices unchanged, with one renter at each integer reservation price between one and eleven, inclusive, the supply side of our market now consists of six landlords, all of whom have a reservation price of 1 . This provides a model whose Walrasian equilibrium price and output would be the same as our base-case market operated under Walrasian conditions. ${ }^{37}$

With perfectly inelastic supply, imposition of a rent ceiling, whether above or below the Walrasian equilibrium price, will have no "supply effect" as long as the ceiling price is above the landlords' (common) reservation supply price. Consequently, the only way that rental price ceilings can affect total surplus in the market is through the "equalizing effect," which encourages the displacement of high reservation-price renters by low reservation-price renters. As in our base-case simulations, imposition of price ceilings affects the distribution of surplus among renters, and between renters and landlords, by altering the outcome of the Nash bargaining process between renters and landlords. In this 
inelastic-supply case, they do so only through their impact on the "equalizing effect," the "bargaining strength effect," and the “direct price ceiling effect.”

[Figure 8 about here]

Figure 8 shows the average values for total surplus, renter surplus and landlord surplus for the unconstrained market at each integer price ceiling. In the base-case simulations we observed that imposing price ceilings above the WEP actually increased total surplus, but that total surplus dropped below the unconstrained level at ceiling prices below the Walrasian competitive price. In the perfectly inelastic-supply case total surplus declines monotonically with the price ceiling. This occurs both because price ceilings do not reduce the extent of trading by extramarginal landlords and renters and because the equalizing effect of price ceilings increases the probability that low-reservation-price renters will successfully conclude bargains and therefore displace high-reservation-price renters. As was true in the base-case simulations, landlord surplus declines with the price ceiling. Renter surplus, however, rises with each successive drop in the ceiling price because there is no supply effect of lowering the price ceiling to cause there to be an interior maximum for renter surplus as occurred in the base-case simulations.

Figure 9 shows the total surplus received by each renter at each rental ceiling price for our inelastic-supply simulations. Rent ceilings do not confer equal gains on all categories of renters: at the rent ceiling levels that significantly alter the market outcome, it is the high-reservation-price renters who receive most of the gains. However, there are some significant differences between the results of the base-case and the perfectly inelastic-supply simulations. First, in contrast to the base-case simulations, price ceilings that are well above the Walrasian competitive price have only a very modest impact on renters' surplus. As the price ceiling falls to nine and below, however, we begin to see more of an impact on renter surplus, particularly for the high-reservation price renters. Also in contrast to the base-case, 
renters with reservation prices as low as three begin to enjoy gains even with price ceilings levels as high as six, and both the number of renter types that gain, and the gains for each type, grow as the ceiling price is successively reduced.

[Figure 9 about here]

Table 6 below reveals another difference between the perfectly inelastic supply case and the basecase simulations: ${ }^{38}$ In our inelastic supply simulations the gains to low-reservation-price renters are significant relative to their reservation prices. For example, price ceilings as high as four or five yield gains in the range of $8 \%$ to $14 \%$ of reservation price to renters 3 and 4 , and lower price ceilings yield progressively larger gains. The reason for this difference between the two cases is relatively straightforward: in our base-case simulations, while low-reservation-price renters benefited from the equalizing effect and direct-price-ceiling effect of lowered price ceilings, the combined impacts of the supply effect and the bargaining strength effect served to offset those benefits; here these effects are absent. $^{39}$

\section{[Table 6 about here]}

Although our simulation results suggest that, under conditions of perfectly inelastic supply, rent ceilings can improve the welfare of poorer renters as well as those with high reservation prices, ${ }^{40}$ the gains to those agents come at a cost, which is consistent with the analyses of Glaeser-Luttmer (2003), Arnott (1995) and Gode and Sunder (1999) to which we referred above. In our perfectly-inelastic-supply simulations, total surplus declines monotonically as the rental price ceiling is lowered, and does so entirely as the consequence of the displacement of high-reservation-price renters by low-reservation price renters. In these simulations, total surplus is about $16 \%$ lower with a price ceiling of two than it is in the unconstrained case, and if the price ceiling is lowered to one, that loss is increased to $24 \%$. 


\section{POLICY IMPLICATIONS}

Drawing sensible policy implications from a highly stylized model is always difficult: we recognize the many variables that our model does not include as well as our restrictive assumptions regarding the nature of the bargaining process between landlords and renters. But with these caveats in mind, we will proceed in the usual fashion to extrapolate from the results of a simple model to derive guidance for policy in a complicated world.

Several results that emerge from our agent-based modeling exercise beg to be taken into account in policy discussions of rent ceilings. One is that in the non-Walrasian setting, the unconstrained market equilibrium is not necessarily the one that maximizes total surplus. ${ }^{41}$ This has several implications. First, to the extent that rental housing markets are non-Walrasian rather than Walrasian, policy analyses that build upon a Walrasian foundation are likely to be flawed. For example, in a Walrasian context, to observe that imposing a rent ceiling reduces the number of units sold in the market would be taken as clear evidence of policy-induced inefficiency. In a non-Walrasian context there may be too many units sold in the unconstrained equilibrium and therefore such a reduction in units could be welfare increasing rather than decreasing. Other policy analyses that assume Walrasian outcomes in the absence of rent controls are subject to similar limitations.

Another result with potential policy implications is that price ceilings that would be "ineffective" in a Walrasian setting, that is price ceilings above the Walrasian equilibrium price, can be “effective” in a non-Walrasian setting in the sense that they can alter the market outcome. However, an effective price constraint need not make for "effective" policy as we usually define the term. Although our base-case results suggest that setting the rental price ceiling at the right level can increase total surplus, the asymmetry between the gains in total surplus from setting the rent control price at the optimum level and the losses from getting the price wrong suggests the need for caution in implementing such policies. In 
our base-case simulations (see Figure 4 above), setting a rent ceiling of 8 increases total surplus by $4.1 \%$ relative to the unconstrained market equilibrium, while setting it at 4 causes a $28.9 \%$ loss of surplus. These are not modest asymmetries.

The distributional impacts of rent controls provide a second reason for caution in implementing rent controls. In our base-case simulations, the impact of rental price ceilings is not always such as to leave the lowest reservation-price renters, whom we equate by assumption with lower income renters, better off; indeed, in some cases they are left worse off. When the price ceiling is set low enough to substantially benefit the low-reservation-price renters, those benefits are likely to come at a cost of substantial losses of total surplus. Even when housing supply is perfectly inelastic, imposing rent ceilings inevitably causes total surplus to fall as low-reservation-price renters displace those who value rental housing more highly.

[Figure 10 about here]

Figure 10 shows the choice frontier between the Gini ${ }_{0}$ coefficient for the distribution of renter surplus (as a measure of inequality in housing outcomes) and total surplus in our base-case market. The selection of an outcome along this choice frontier would naturally depend on the social welfare function that motivated the policy decisions. The figure illustrates three possible optimizing choices. If the social welfare function attaches a large marginal value to equality, then a choice such as point A (rent ceiling between 3 and 4) might be optimal. Often, however, choice B (no rent ceiling) will offer higher total social welfare, as in the example illustrated. A policy maker very concerned about total surplus might opt for outcome $\mathrm{C}$ (rent ceiling of 8), but this requires that the marginal valuation of total surplus be very high relative to the marginal valuation of equality. Under demand and supply conditions that approximate those in our base-case simulations, at least, it would seem that the tradeoffs are not in general such as to favor rent controls as a device for achieving equality. 
Our results raise intriguing questions regarding the political economy of rent controls. To the extent that our results reflect the real-world distributional consequences of rent controls, they predict that renters with reservation prices greater than the WEP will favor any rent ceiling that is below their own reservation price but not so low as to dramatically reduce supply. Renters with reservation prices strictly below the WEP favor any rent ceiling that is below the WEP but not so low as to deny all surplus even to the lowest reservation price landlords. The exception to this would be situations in which housing supply is quite unresponsive to price.

At least two other factors complicate the full determination of voting patterns. First, because rent controls will typically increase the dispersion of outcomes among renters, if renters are risk averse then their support for rent ceilings will depend upon more than just the change in their expected surplus. Second, because rent controls alter the probabilities that renters of different income levels will secure a rental unit with the affected market, and because enfranchisement typically requires residence, political support for rent controls is endogenous to the adopted rent control policy.

\section{CONCLUSIONS}

In this paper we use agent-based models to derive several results regarding the impact of rent ceilings in non-Walrasian housing markets. We find that the non-Walrasian market outcome differs from the Walrasian competitive equilibrium in many ways, and that those differences cause the impact of rent ceilings in such markets to be different as well.

Consider first our base-case simulation results. In this non-Walrasian setting, agents who would be extramarginal traders in the Walrasian setting do get to trade some of the time; indeed, renters (landlords) whose reservation prices are not far below (above) the Walrasian equilibrium price (WEP) account for a significant share of the units rented. This has several implications. First, because some exchanges do occur at prices above the WEP in the non-Walrasian setting, price ceilings above the WEP, 
which would be non-binding in a Walrasian setting, can affect the market outcome. Second, because the equilibrium number of trades in the non-Walrasian setting exceeds the surplus-maximizing number, rent ceilings that reduce the number of units rented do not necessarily reduce total market surplus; indeed, a rent ceiling set somewhat above the WEP can act to increase total surplus. Third, the fact that renters with reservation prices below the WEP do manage to successfully rent in a non-Walrasian setting causes the distributional impact of rent controls to differ from that in a Walrasian setting.

Although our base-case simulation results show that rent ceilings can in some circumstances increase total surplus, our results do not provide strong support for the use of rent controls. Rather, our results suggest that at most rent ceiling levels, the great preponderance of the gains to renters go to high reservation price renters rather than those with low reservation prices, exacerbating inequality while achieving little benefit for the poorest renters. ${ }^{42}$ To make the poorest renters substantially better off in circumstances corresponding to our base-case conditions requires rent ceilings so low that the gain to the low reservation-price renters is disproportionately small relative to the total sacrifice in total surplus. Indeed, under our assumptions regarding the distributions of renters’ and landlords' reservation prices and the nature of the market process, it is not even possible to impose rent ceilings that would significantly benefit what one might think of as "working poor" — in our example renters with reservation prices of 4 and 5, somewhat but not too much below the mean - without incurring losses in total surplus of about $14 \%$ relative to the unconstrained market. The asymmetry between the increases in total surplus that can be obtained by choosing the right rental price ceiling and the decreases that result from choosing the wrong ceiling price provide further grounds for caution in implementing rental price ceilings.

Our simulation results under conditions of perfectly inelastic supply, not surprisingly, are more optimistic regarding the opportunities for using rental price ceilings as a redistributive mechanism. The absence of any supply response to rent ceilings not only ensures that low-reservation-price renters will not suffer reductions in surplus when rent ceilings are imposed, but also ensures that the tradeoffs between redistributive goals and total surplus are not as unfavorable as when housing supply is 
responsive to price. Redistribution does carry a cost in terms of total surplus even in the perfectly inelastic supply case of course, as binding rent ceilings cause high-reservation-price renters to be displaced in the housing market by low-reservation-price renters.

On a more general note, our model results demonstrate the potential of the agent-based modeling approach and the opportunities for further applications of the methodology. Clearly we have not exhausted the range of possible supply and demand conditions and of possible price-setting mechanisms. We have also not incorporated search costs, temporal discounting, or housing quality heterogeneity into our model. Our results suggest that these research avenues too may contribute to developing a more nuanced understanding of the impact of rent ceilings. It should also be apparent that our modeling approach is a very general one, and that just as agent-based modeling provides a way to address rental housing issues that have so far resisted purely analytical approaches, it also provides a way to address other issues such as the impact of price ceilings or price floors in other contexts including that of the impact of minimum wage laws. 


\section{REFERENCES}

Alston, Richard, Kearl, J. R., and Vaughan, Michael (1992), "Is There a Consensus Among Economists in the 1990's?” American Economic Review Papers and Proceedings 82:203-209.

Arnott, Richard. (1995) “Time For Revisionism on Rent Control?” Journal of Economic Perspectives, 9: 99-120.

Arnott, Richard and Masashiro Igarashi. (2000) "Rent Control, Mismatch Costs and Search Efficiency," Regional Science and Urban Economics 30: 249-288.

Cottle, Rex and Myles Wallace. (1982) “The Effectiveness of Supposedly Ineffective Price Constraints,” Atlantic Economic Journal, 10: 71-76.

Fershtman, Chaim and Arthur Fishman. (1994) "The 'Perverse' Effects of Wage and Price Controls in Search Markets,” European Economic Review 38: 1099-1112.

Glaeser, Edward. (1996) “The Social Costs of Rent Control Revisited,” NBER Working Paper No. 5441.

Glaeser, Edward and Erzo F.P. Luttmer. (2003) "The Misallocation of Housing Under Rent Control." American Economic Review, 93: 1027 - 1046.

Gode, Dhananjay and Shyam Sunder. (1997) “What Makes Markets Allocatively Efficient,” Quarterly Journal of Economics 112 603-630.

Gode, Dhananjay and Shyam Sunder. (1999) "Double Auction Dynamics: Structural Consequences of Non-Binding Price Controls," mimeo. Available for download in PDF format from http://www.gsia.cmu.edu/andrew/sunder/limit.pdf

Gyourko, Joseph and Peter Linneman. (1989) "Equity and Efficiency Aspects of Rent Control: An Empirical Study of New York City”, Journal of Urban Economics 26:54-74.

Malpezzi, Stephen and Duncan Maclennan, (2001) “The Long-Run Price Elasticity of Supply of New Residential Construction in the United States and the United Kingdom”, Journal of Housing Economics, 10:278-306.

Munch, Jakob Roland and Svarer, Michael, (2002) “Rent Control and Tenancy Duration”, Journal of Urban Economics, 52, 542-560.

Nagy, John (1995) “Increased Duration and Sample Attrition in New York City's Rent Controlled Sector”, Journal of Urban Economics, 38, 127-137.

Rauh, Michael T. (2001) "Heterogenous Beliefs, Price Dispersion, and Welfare-Improving Price Controls,” Economic Theory 18: 577-603.

Rauh, Michael T. (2002) "Wage and Price Controls in the Equilibrium Sequential Search Model”, mimeo, University of Liverpool, 2002. 
Olsen, Edgar (1998) "Economics of Rent Control", Regional Science and Urban Economics, 28: 673678.

Osborne, Martin and Rubinstein, Ariel, (1990) Bargaining and Markets, Academic Press, Cambridge, MA.

Rubinstein, Ariel, (1982) “Perfect Equilibrium in a Bargaining Model”, Econometrica, 50: 97-110.

Sah, Raaj Kumar. (1987) "Queues, Rations, and Market: Comparison of Outcomes for the Poor and the Rich,” American Economic Review 77: 69-77.

Suen, Wing. (1989) "Rationing and Rent Dissipation in the Presence of Heterogeneous Individuals," Journal of Political Economy, 97: 1384-1394.

Smith, Adam. (1776) An Inquiry into the Nature and Causes of the Wealth of Nations. Ed. Edwin Cannan. (New York, Modern Library, 1937). 
Tables to be placed in text

\begin{tabular}{|c|c|c|c|c|c|c|c|c|c|c|c|c|c|}
\hline & TABL & E 1: C & OUNT & OF TF & RANSA & $\begin{array}{l}\text { CTIONS } \\
\text { RENTE }\end{array}$ & $\begin{array}{l}\text { BY REI } \\
\text { TYPE }\end{array}$ & ITER AI & ID LAN & DLORD & TYPE & & \\
\hline LANDLORD & & & & & & & & & & & & & \\
\hline TYPE & 1 & 2 & 3 & 4 & 5 & 6 & 7 & 8 & 9 & 10 & 11 & $\#$ & $\%$ \\
\hline 1 & 0 & 0 & 1243 & 3382 & 3101 & 2687 & 2380 & 2148 & 1874 & 1660 & 1525 & 20000 & 15.56 \\
\hline 2 & 0 & 0 & 0 & 2626 & 3471 & 3086 & 2722 & 2429 & 2110 & 1895 & 1661 & 20000 & 15.56 \\
\hline 3 & 0 & 0 & 0 & 68 & 3297 & 4091 & 3389 & 2793 & 2425 & 2093 & 1844 & 20000 & 15.56 \\
\hline 4 & 0 & 0 & 0 & 0 & 114 & 3834 & 4461 & 3555 & 2805 & 2432 & 2049 & 19250 & 14.98 \\
\hline 5 & 0 & 0 & 0 & 0 & 0 & 1119 & 4153 & 4272 & 3333 & 2780 & 2429 & 18086 & 14.07 \\
\hline 6 & 0 & 0 & 0 & 0 & 0 & 0 & 89 & 3954 & 4006 & 2981 & 2643 & 13673 & 10.64 \\
\hline 7 & 0 & 0 & 0 & 0 & 0 & 0 & 0 & 80 & 3375 & 3607 & 2922 & 9984 & 7.77 \\
\hline 8 & 0 & 0 & 0 & 0 & 0 & 0 & 0 & 0 & 72 & 2552 & 3287 & 5911 & 4.60 \\
\hline 9 & 0 & 0 & 0 & 0 & 0 & 0 & 0 & 0 & 0 & 0 & 1640 & 1640 & 1.28 \\
\hline 10 & 0 & 0 & 0 & 0 & 0 & 0 & 0 & 0 & 0 & 0 & 0 & 0 & 0.00 \\
\hline 11 & 0 & 0 & 0 & 0 & 0 & 0 & 0 & 0 & 0 & 0 & 0 & 0 & 0.00 \\
\hline \# & 0 & 0 & 1243 & 6076 & 9983 & 14817 & 17194 & 19231 & 20000 & 20000 & 20000 & 128544 & \\
\hline$\%$ & 0.00 & 0.00 & 0.97 & 4.73 & 7.77 & 11.53 & 13.38 & 14.96 & 15.56 & 15.56 & 15.56 & & \\
\hline
\end{tabular}

\begin{tabular}{|l|l|}
\hline $\begin{array}{l}\text { Rent } \\
\text { Ceiling }\end{array}$ & $\begin{array}{l}\text { Average } \\
\text { Quantity } \\
\text { Exchanged }\end{array}$ \\
\hline 2 & 2.00 \\
\hline 3 & 3.00 \\
\hline 4 & 4.00 \\
\hline 5 & 5.00 \\
\hline 6 & 5.98 \\
\hline 7 & 6.44 \\
\hline 8 & 6.23 \\
\hline 9 & 6.31 \\
\hline 10 & 6.42 \\
\hline 11 & 6.43 \\
\hline Table 2: Average Volume Of \\
Rentals At Each Rent Ceiling \\
\hline
\end{tabular}




\begin{tabular}{|c|c|c|c|c|c|c|c|c|c|c|}
\hline \multicolumn{11}{|c|}{$\begin{array}{c}\text { Table 3: Percentage Of Rentals Accounted For By } \\
\text { Each Renter Type At Each Rent Ceiling }\end{array}$} \\
\hline \multicolumn{11}{|c|}{ Rent Ceiling } \\
\hline & 2 & 3 & 4 & 5 & 6 & 7 & 8 & 9 & 10 & 11 \\
\hline $\mathbf{1}$ & 0.0 & 0.0 & 0.0 & 0.0 & 0.0 & 0.0 & 0.0 & 0.0 & 0.0 & 0.0 \\
\hline 2 & 5.3 & 3.7 & 0.0 & 0.0 & 0.0 & 0.0 & 0.0 & 0.0 & 0.0 & 0.0 \\
\hline 3 & 10.2 & 7.5 & 6.5 & 2.9 & 2.4 & 1.9 & 1.2 & 1.2 & 1.2 & 1.0 \\
\hline 4 & 10.4 & 11.1 & 9.3 & 7.0 & 5.1 & 4.8 & 4.6 & 4.3 & 4.3 & 4.7 \\
\hline 5 & 10.4 & 11.1 & 12.0 & 10.7 & 9.0 & 7.3 & 7.5 & 7.7 & 7.5 & 7.8 \\
\hline 6 & 10.7 & 11.0 & 12.0 & 13.1 & 12.0 & 11.0 & 10.2 & 10.4 & 11.4 & 11.5 \\
\hline 7 & 10.6 & 11.1 & 12.2 & 13.2 & 13.9 & 13.6 & 12.7 & 13.8 & 13.9 & 13.4 \\
\hline 8 & 10.6 & 11.2 & 12.0 & 13.2 & 14.3 & 15.3 & 15.9 & 14.9 & 14.9 & 15.0 \\
\hline 9 & 10.7 & 11.2 & 12.1 & 13.3 & 14.5 & 15.4 & 16.0 & 15.9 & 15.6 & 15.6 \\
\hline 10 & 10.4 & 11.1 & 11.8 & 13.3 & 14.4 & 15.4 & 16.0 & 15.9 & 15.6 & 15.6 \\
\hline 11 & 10.7 & 11.1 & 12.1 & 13.3 & 14.4 & 15.4 & 16.1 & 15.9 & 15.6 & 15.6 \\
\hline
\end{tabular}

\begin{tabular}{|c|c|c|}
\hline \multicolumn{3}{|c|}{ Table 4: Gini coefficients at each level } \\
of constraint
\end{tabular}

\begin{tabular}{|c|c|c|c|c|c|c|c|c|c|c|}
\hline \multirow[b]{2}{*}{$\begin{array}{l}\text { Reservation } \\
\text { Price }\end{array}$} & \multicolumn{8}{|c|}{$\begin{array}{c}\text { Table 5: Change in Renter Surplus as a Percent of Reservation Price } \\
\text { Rent Ceiling }\end{array}$} & \multirow[b]{2}{*}{9} & \multirow[b]{2}{*}{10} \\
\hline & 1 & 2 & 3 & 4 & 5 & 6 & 7 & 8 & & \\
\hline 1 & 0.00 & 0.00 & 0.00 & 0.00 & 0.00 & 0.00 & 0.00 & 0.00 & 0.00 & 0.00 \\
\hline 2 & 4.54 & 1.52 & 0.52 & 0.00 & 0.00 & 0.00 & 0.00 & 0.00 & 0.00 & 0.00 \\
\hline 3 & 5.70 & 7.14 & 2.92 & 1.98 & 1.07 & 0.59 & 0.28 & -0.03 & 0.10 & 0.10 \\
\hline 4 & 2.47 & 6.67 & 6.07 & 1.90 & 0.74 & 0.18 & -0.18 & -0.41 & -0.31 & -0.26 \\
\hline 5 & -2.12 & 3.88 & 5.79 & 4.34 & 0.25 & -0.09 & -0.79 & -0.71 & -0.37 & -0.35 \\
\hline 6 & -7.85 & -0.31 & 2.93 & 4.29 & 2.08 & -1.08 & -1.56 & -1.65 & -1.05 & -0.30 \\
\hline 7 & -12.42 & -4.73 & -0.04 & 3.54 & 3.63 & 1.50 & -1.50 & -1.92 & -0.79 & -0.12 \\
\hline 8 & -16.16 & -8.17 & -2.36 & 1.92 & 4.81 & 4.27 & 2.97 & -0.62 & -0.48 & -0.17 \\
\hline 9 & -19.15 & -9.98 & -3.66 & 2.04 & 6.77 & 8.04 & 6.99 & 4.82 & -0.64 & 0.28 \\
\hline 10 & -20.43 & -11.55 & -4.19 & 1.87 & 8.39 & 11.50 & 10.93 & 9.82 & 5.62 & -0.05 \\
\hline 11 & -21.24 & -11.97 & -4.79 & 2.79 & 9.66 & 14.47 & 14.47 & 13.56 & 10.24 & 5.15 \\
\hline
\end{tabular}




\begin{tabular}{|l|rccccccccr||}
\hline \multicolumn{3}{|c|}{ Table 6: Change in Renter Surplus as a Percent of Reservation Price with Inelastic Supply } \\
\begin{tabular}{|l} 
Reservation \\
Price
\end{tabular} & 1 & 2 & 3 & 4 & 5 & 6 & 7 & 8 & 9 & 10 \\
1 & 0.00 & 0.00 & 0.00 & 0.00 & 0.00 & 0.00 & 0.00 & 0.00 & 0.00 & 0.00 \\
2 & 27.25 & 12.13 & 1.39 & 0.00 & 0.00 & 0.00 & 0.00 & 0.00 & 0.00 & 0.00 \\
3 & 36.52 & 25.47 & 17.23 & 14.00 & 9.71 & 1.97 & 0.00 & 0.00 & 0.00 & 0.00 \\
4 & 31.55 & 24.77 & 16.09 & 10.56 & 8.32 & 7.20 & 5.80 & 4.59 & 3.41 & 1.58 \\
5 & 25.32 & 20.87 & 15.06 & 7.82 & 3.44 & 3.61 & 2.74 & 1.44 & 0.46 & 0.07 \\
6 & 22.94 & 20.48 & 16.13 & 9.83 & 3.98 & 2.66 & 2.05 & 1.17 & 0.26 & 0.04 \\
7 & 20.90 & 19.95 & 16.34 & 11.34 & 5.55 & 3.08 & 1.58 & 0.75 & -0.10 & -0.27 \\
8 & 19.52 & 18.52 & 16.70 & 12.61 & 7.46 & 4.65 & 2.47 & 0.30 & -0.34 & -0.33 \\
9 & 18.02 & 18.69 & 17.24 & 13.61 & 9.37 & 7.13 & 4.25 & 1.31 & 0.14 & -0.13 \\
10 & 17.89 & 18.16 & 17.48 & 14.72 & 10.78 & 9.18 & 6.36 & 2.79 & 0.52 & -0.33 \\
11 & 16.90 & 17.53 & 17.23 & 15.28 & 11.57 & 10.39 & 8.24 & 4.53 & 1.96 & 0.31 \\
\hline
\end{tabular}


Figure Captions

Figure 1: Welfare Loss From Rent Control

Figure 2: Average Rental Price by Rent Ceiling

Figure 3: Percent of Rentals to Each Buyer Type

Figure 4: Total Surplus by Rent Ceiling

Figure 5: Percent of Trades by Extramarginal Renters and Landlords

Figure 6: Surplus as a Function of Rent Control

Figure 7: Relation Between Gini and Rent Ceiling

Figure 8: Surplus Levels with Inelastic Supply

Figure 9: Renter Surplus as a Function of Rent Control

Figure 10: Tradeoff Between Gini and Total Surplus 


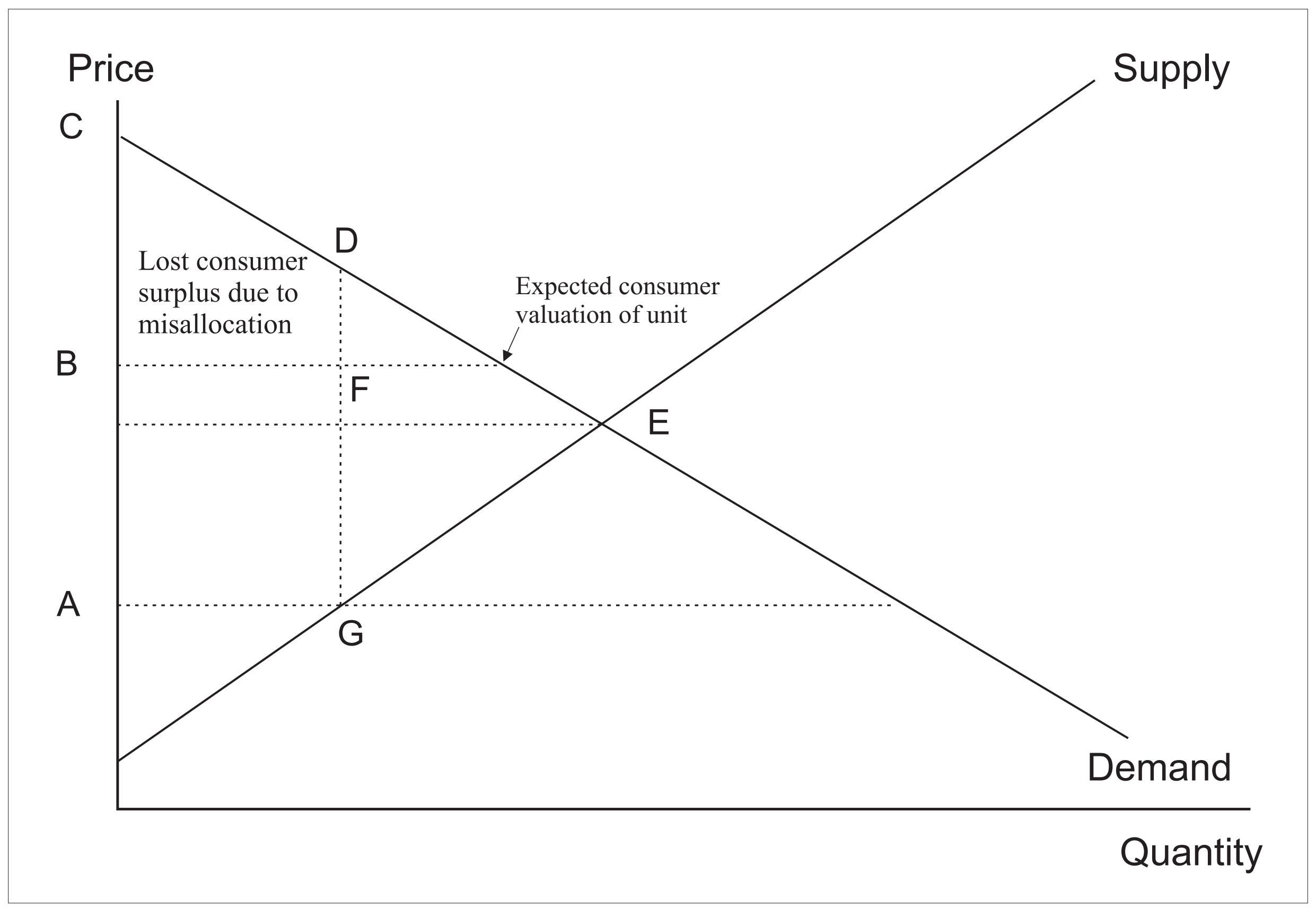




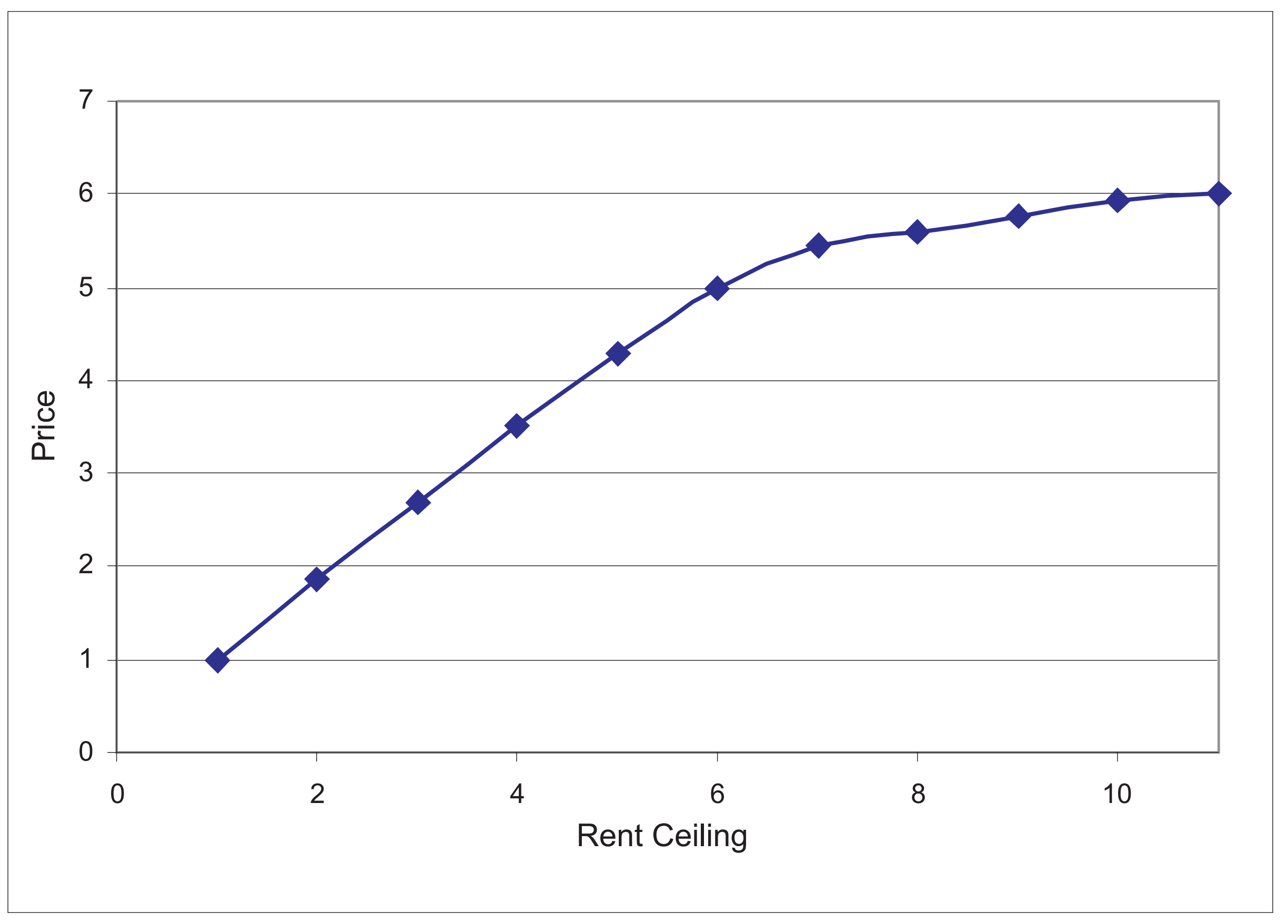




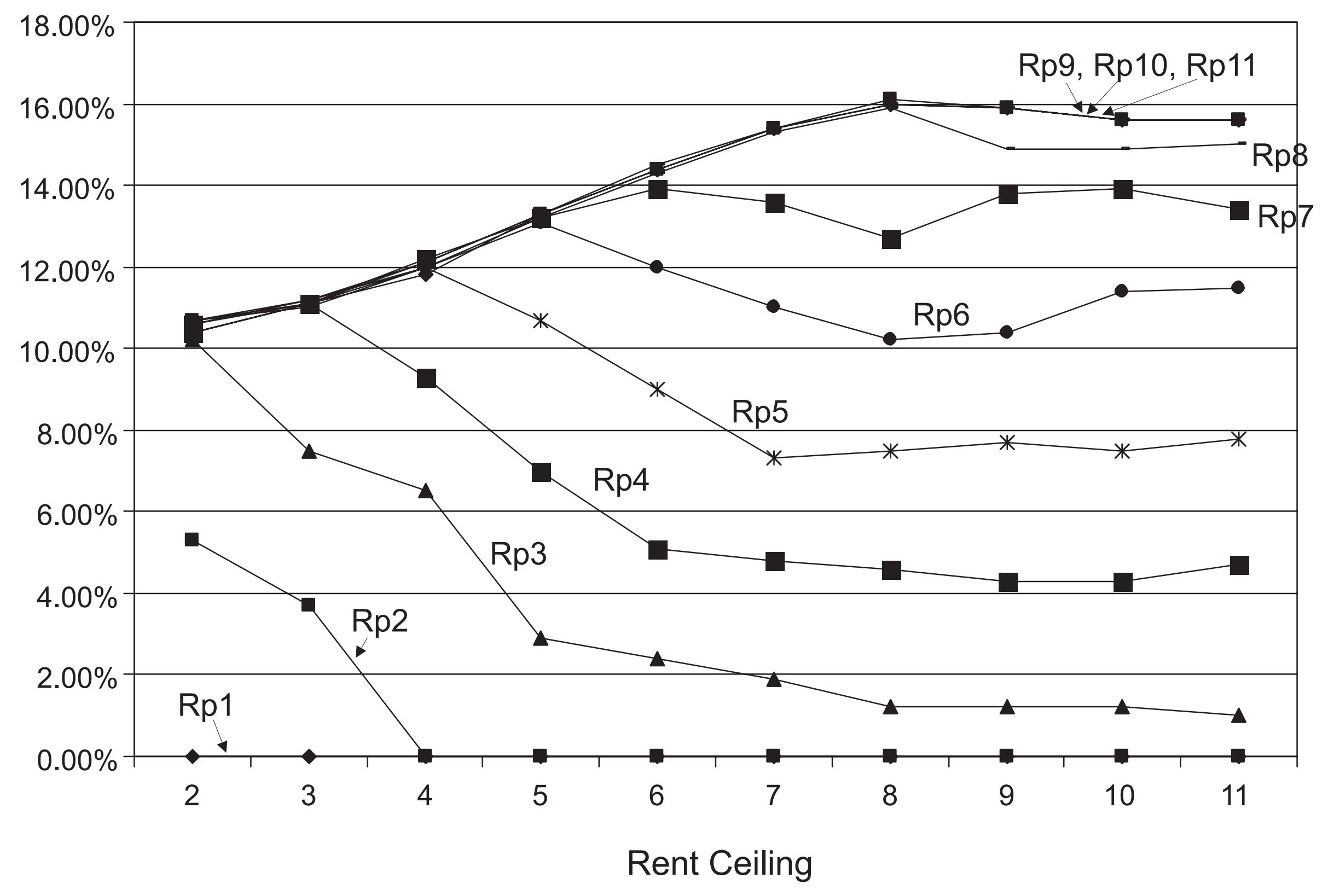




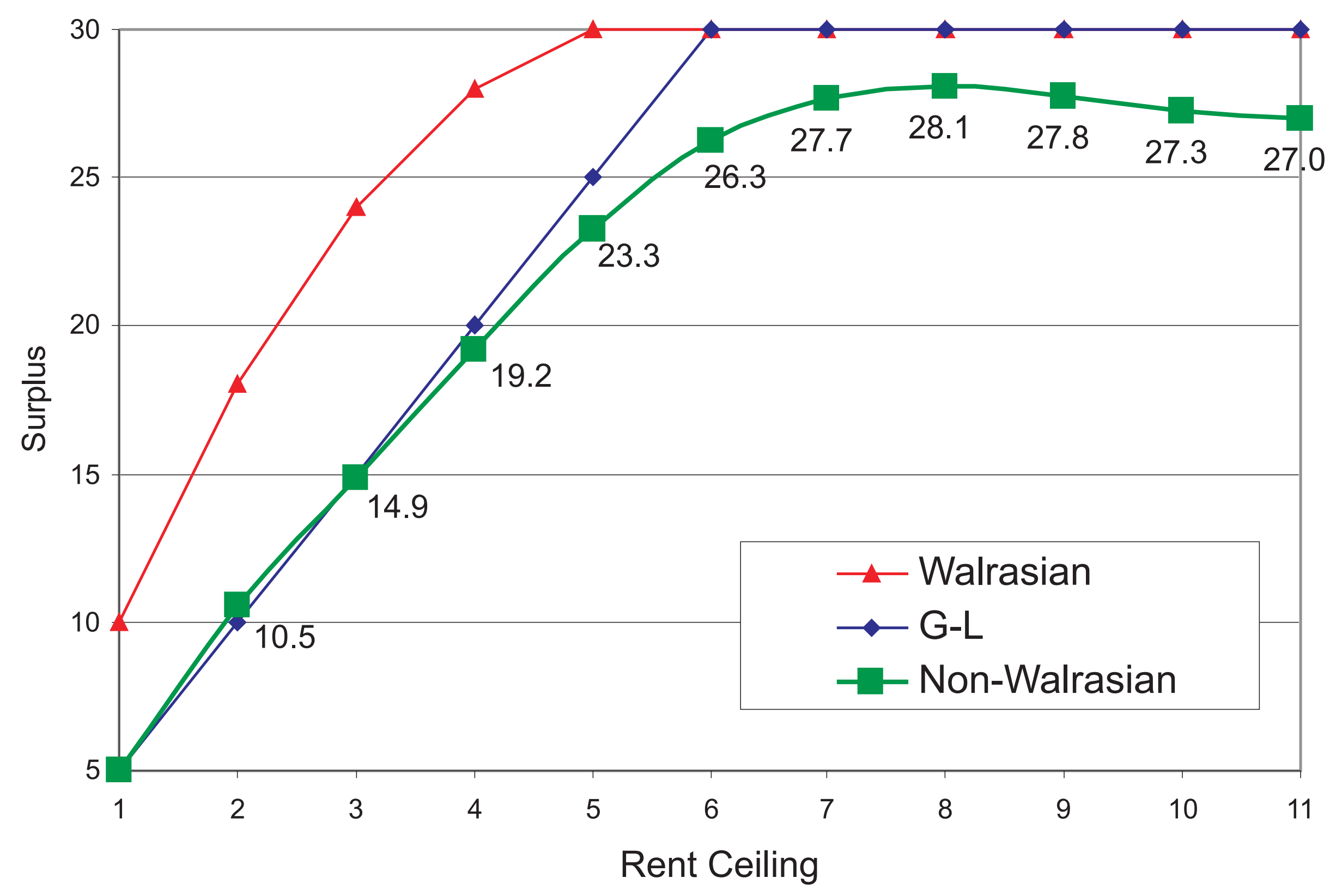




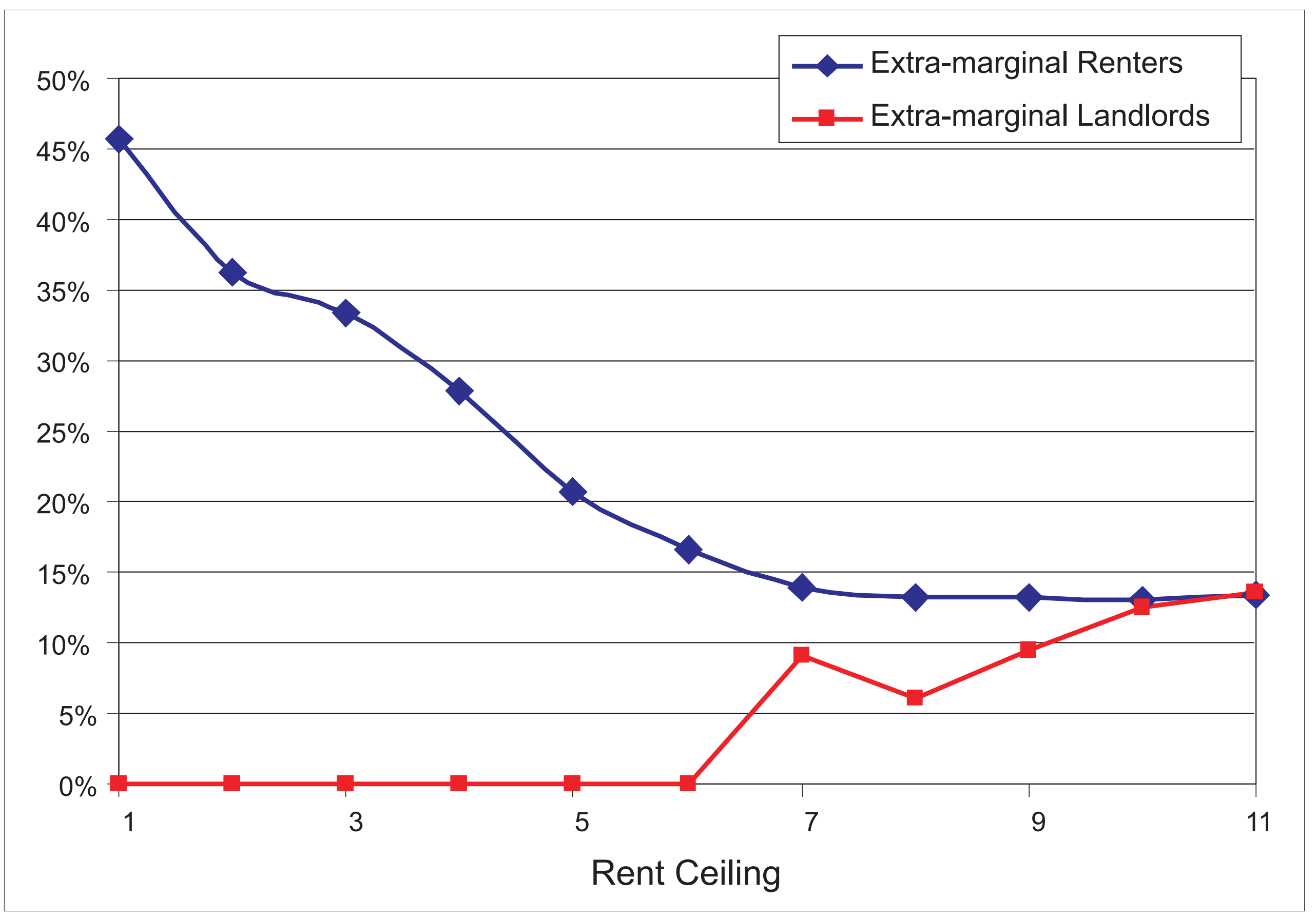




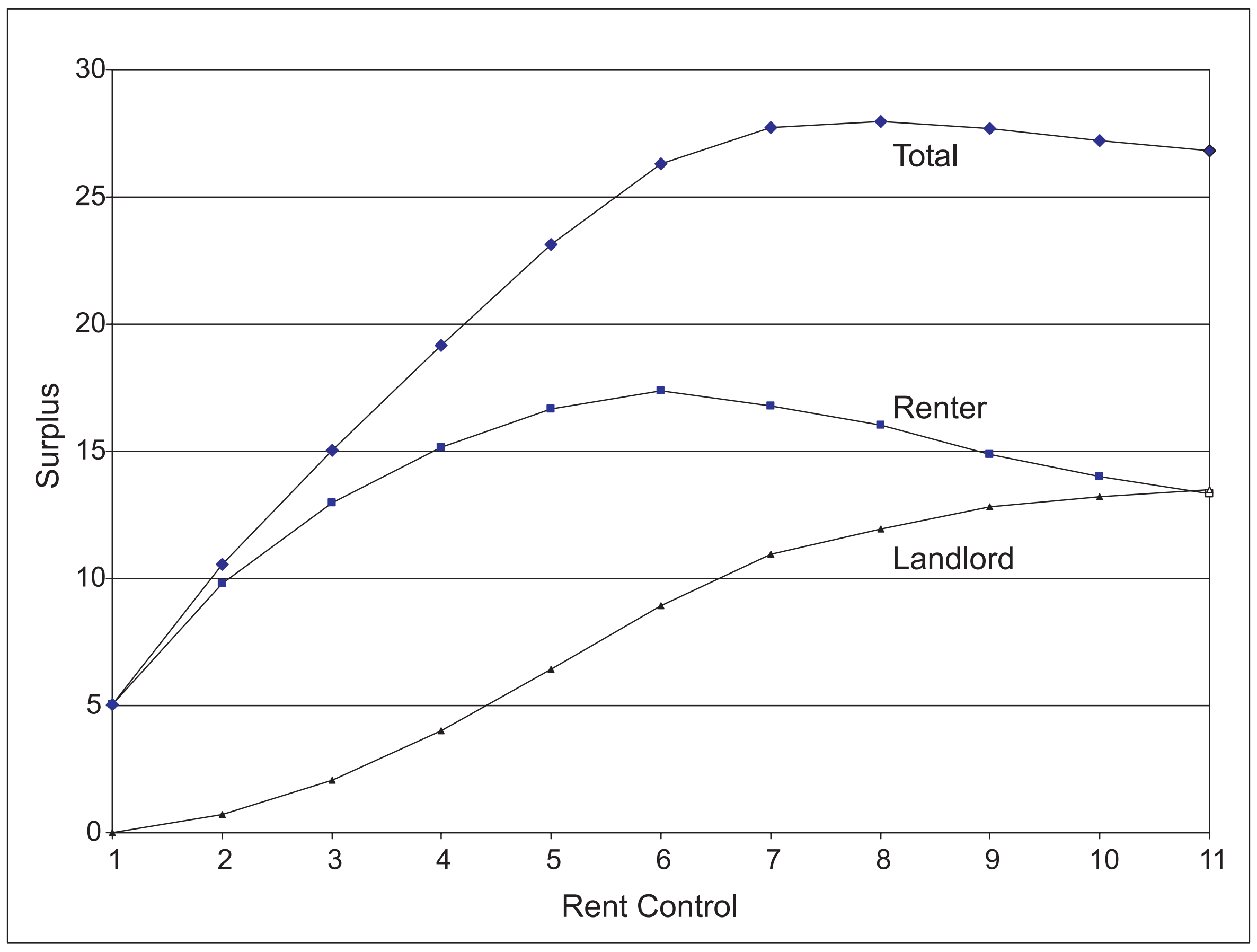




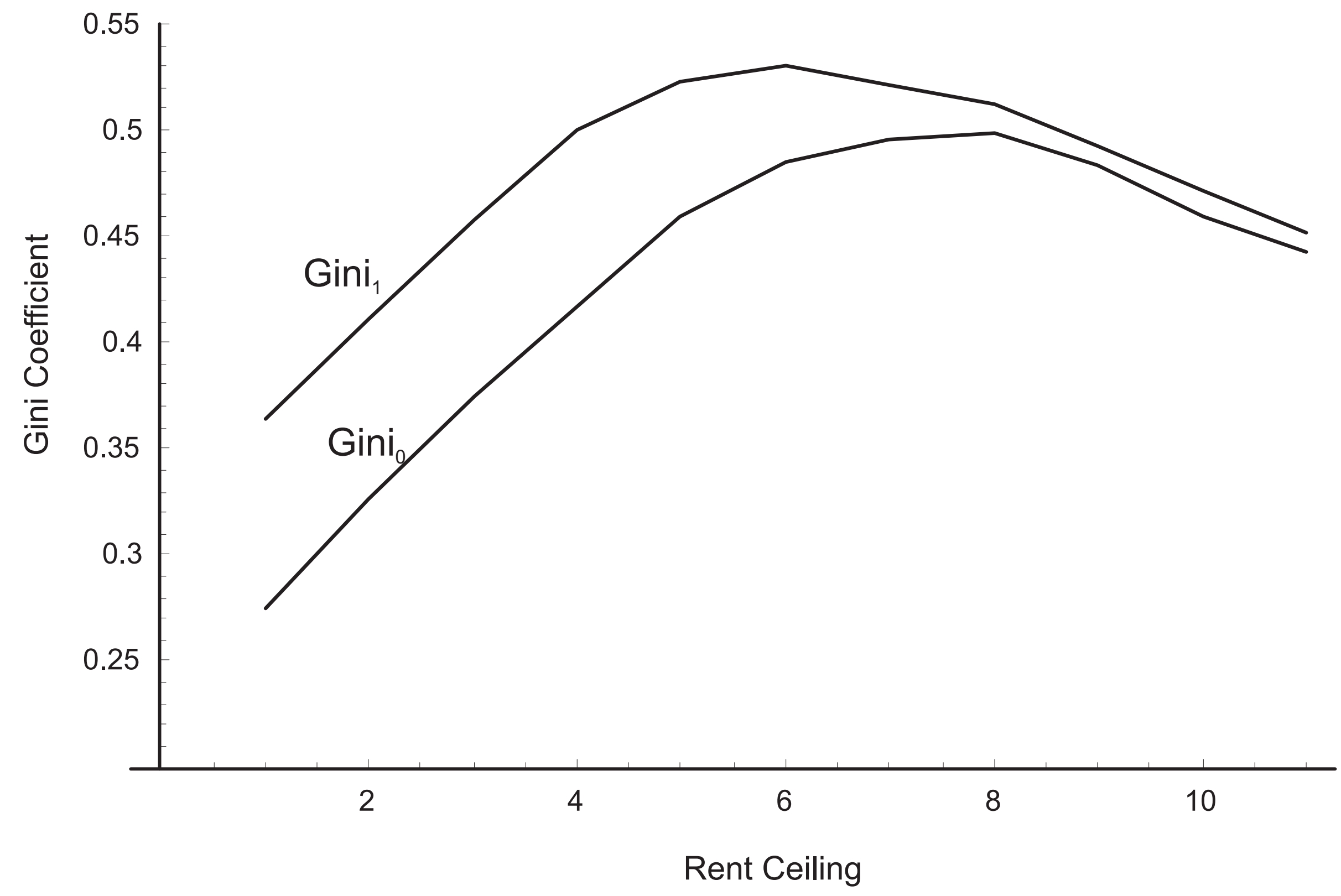




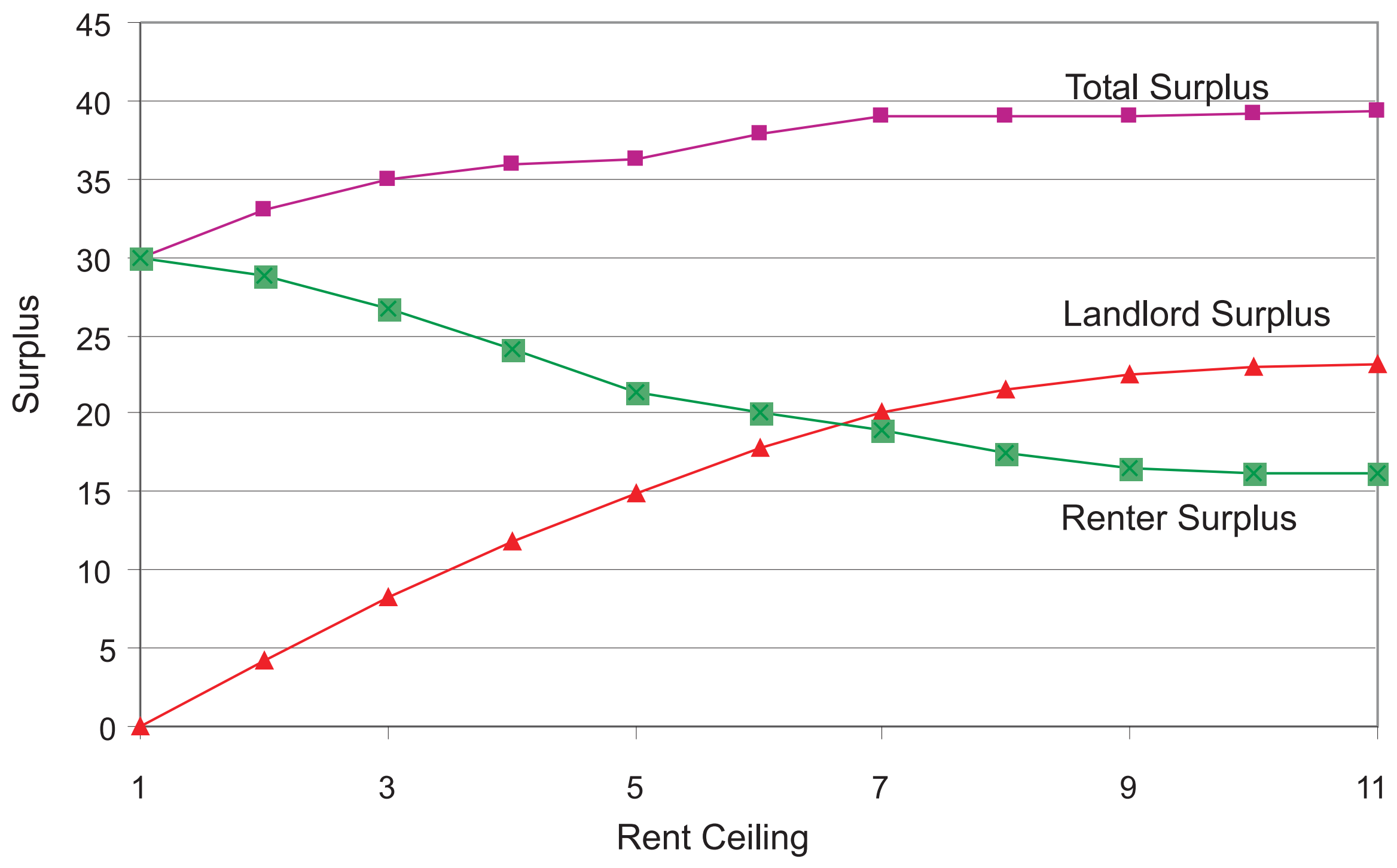




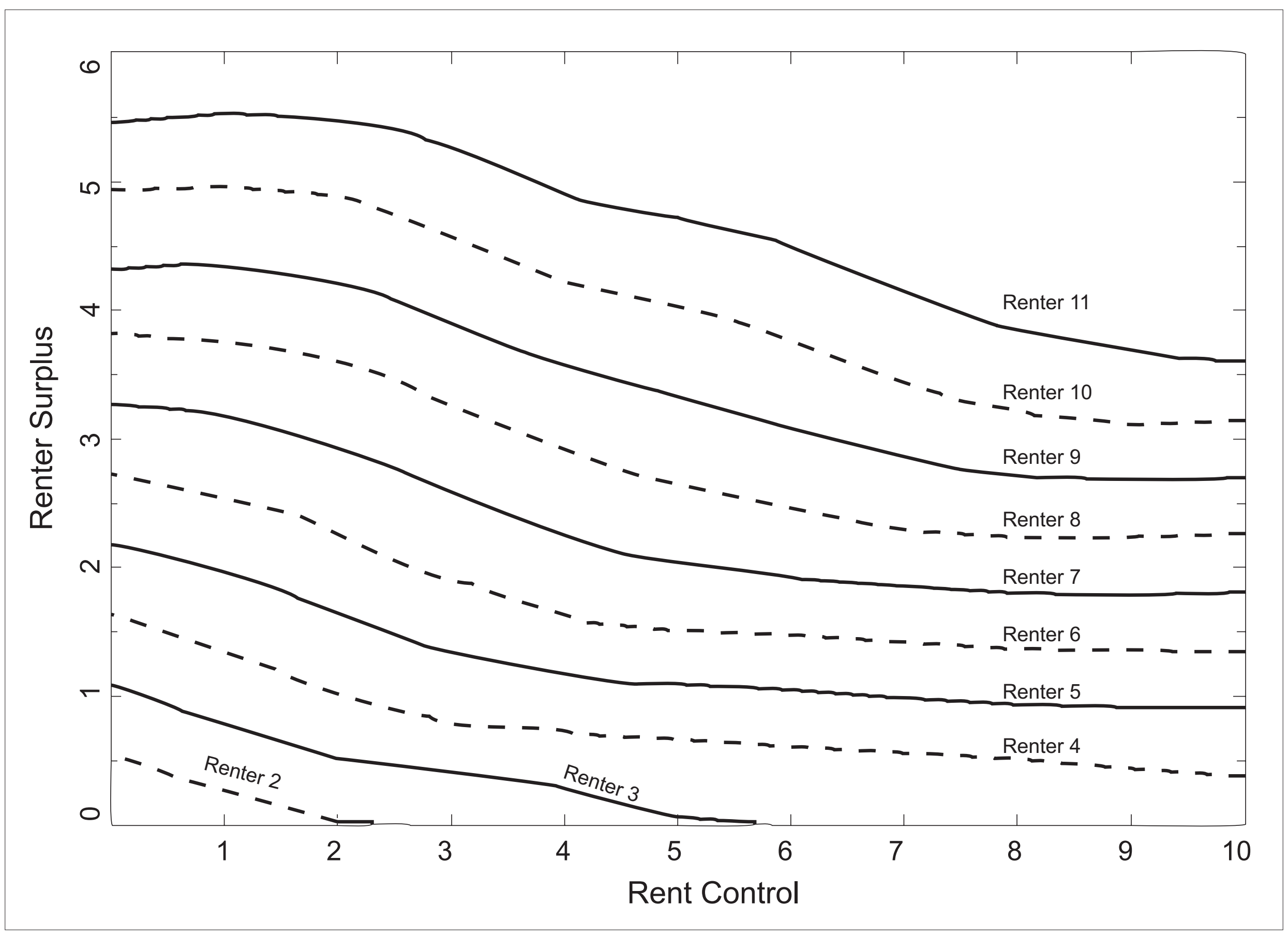




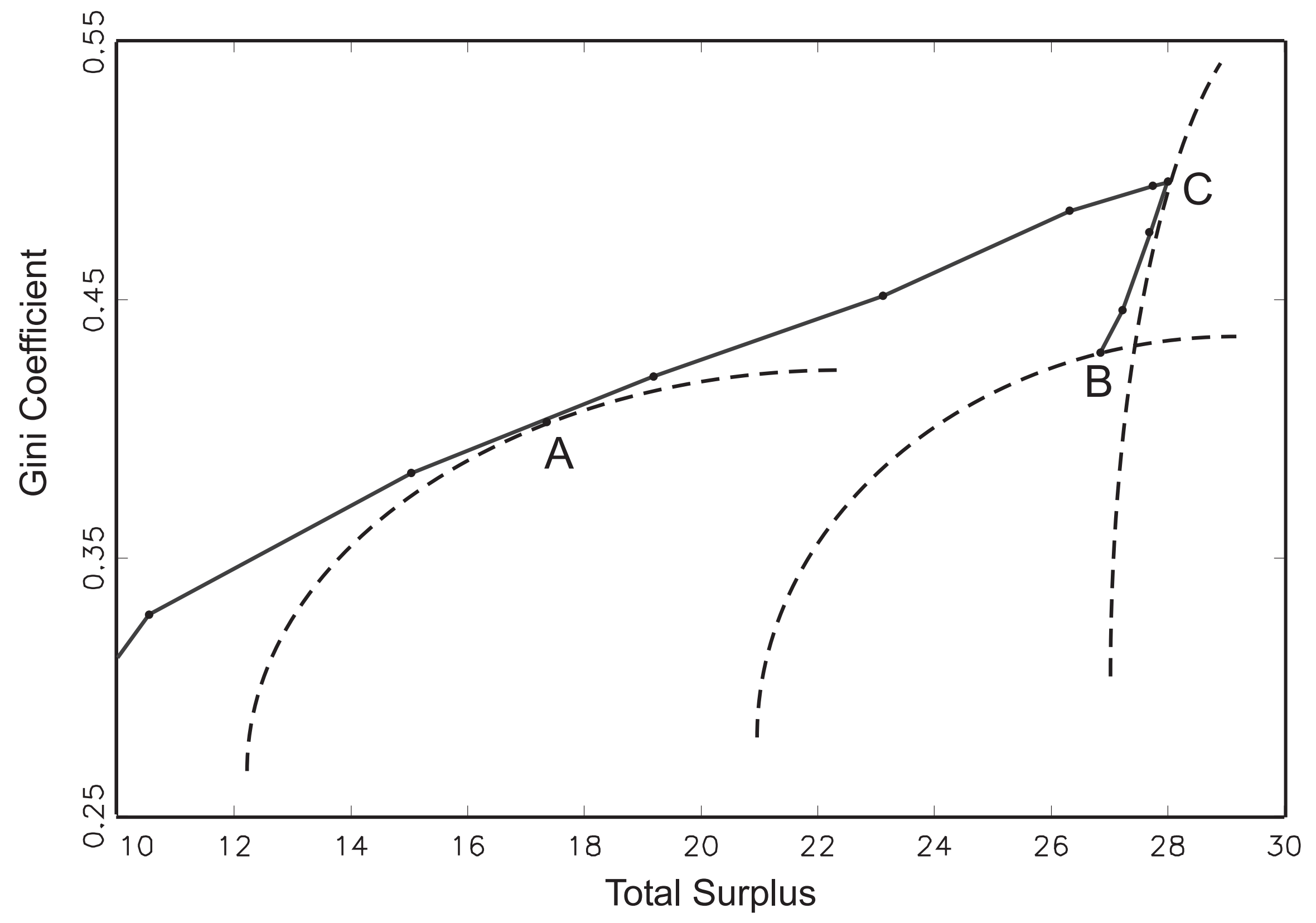




\section{APPENDIX}

\section{Impacts of market size on results}

One possible concern about the results derived from our agent based model is the relatively small number of traders. Perhaps the failure of an unconstrained market to maximize total market surplus is due to the market size. With only 11 buyers and 11 sellers trading in the base case simulations, it might be that the loss in surplus is due to thin markets rather than the exchange mechanism in which renters and landlords encounter each other and bargain. This explanation is not correct. While the surplus achieved does depend on the relative number of traders on each side of the market and, as we have seen above, on the relative elasticity of supply and demand, it appears not to depend on the size of the market.

\begin{tabular}{|cccc|}
\hline \multicolumn{4}{|c|}{ Table A1 } \\
$\begin{array}{c}\text { Total } \\
\text { Rent }\end{array}$ & \multicolumn{4}{c|}{$\begin{array}{c}\text { Agents on each side of market } \\
\text { Control }\end{array}$} & 11 Agents & 110 Agents & 1100 Agents \\
\hline 1 & 16.76 & 16.65 & 16.66 \\
2 & 35.12 & 34.97 & 34.90 \\
3 & 50.10 & 49.56 & 49.64 \\
4 & 63.91 & 64.26 & 64.27 \\
5 & 77.07 & 77.13 & 77.11 \\
6 & 87.71 & 87.52 & 87.54 \\
7 & 92.46 & 92.47 & 92.56 \\
8 & 93.29 & 93.78 & 93.83 \\
9 & 92.32 & 93.21 & 93.40 \\
10 & 90.75 & 91.57 & 91.72 \\
11 & 89.47 & 90.81 & 90.83 \\
\hline
\end{tabular}

Table A1 presents the average total market surplus as a percent of Walrasian surplus at each level of rent control for three different market sizes: our original market with 11 renters and 11 landlords, plus a market with 110 agents on each side, and finally 1100 agents on each side. The range of reservation prices and elasticities of demand and supply were held constant. As seen in the table, expanding the number of agents has virtually no impact on the efficiency of the outcome, with observed differences well within sampling variance. Not reported in the table is an analysis involving 11000 traders on each side of the market with no rent control. Such a market is extremely costly computationally, requiring several days to 
complete an abbreviated set of 10 market rounds (rather than the 20000 used in other cases). For this very large model the mean efficiency over the ten rounds was less than $80 \%$. While not strictly comparable to the other cases presented in table A1, the result is clearly consistent with the observation that increasing the number of traders in the market does not restore the trading process to an outcome of Walrasian efficiency.

\section{Further intuition concerning rent controls in non-Walrasian markets}

It may seem puzzling that rent controls can ever increase total surplus. The key is the nonWalrasian structure of these markets. The stochastic process of matching landlords and renters for bargaining encounters, and the fact that the law of one price does not hold, means that extramarginal trades can occur; this in turn implies that price constraints that inhibit successful trading by extramarginal traders can increase total surplus in the market.

Consider an example even simpler than the one we study: assume there are three landlords with identical units but different marginal costs of offering them as residential units. Let the three landlord's units have marginal costs of 1, 2, and 3, and denote the units as $\mathbf{L 1} \mathbf{L} \mathbf{2}$, and $\mathbf{L} 3$, respectively. There are three possible renters, R1.1, R2.1 and R3.1 with reservation prices of 1.1, 2.1 and 3.1, respectively. These three are indifferent between the units themselves. When a prospective renter encounters a landlord, they discuss terms. If the renter's reservation price is less than the landlord's marginal cost, no deal is possible and the renter and landlord continue to search. If they are compatible, they negotiate to a price that divides the surplus between them. (Unlike the simulation model we employ in the text above, assume that all agents’ disagreement points are equal to zero.)

The Walrasian equilibrium of this residential market allocates a unit each to renters $\mathbf{R 2 . 1}$ and R3.1. Units $\mathbf{L} 1$ and $\mathbf{L} 2$ will be rented. It is not efficient for the high-cost unit $\mathbf{L} 3$ to be in residential use, and it will not be rented (or built). Renter R1.1 will not be accommodated in this market, and will acquire 
substitute shelter in some other market (assume she pays 1.1 in the other market and realizes zero surplus). The equilibrium price would be any price between 2 and 2.1, and the total surplus generated would be 2.2. This corresponds to the standard result in modeling a competitive market outcome.

Non-Walrasian outcomes are also possible. These are illustrated in Table A2, with renters associated with rows and landlords associated with columns. Feasible allocations are illustrated in the matrix by letters in cells identifying the pairings that define the allocation. In an unconstrained market there are 3 feasible allocations: W, $\mathrm{X}$ and Y. Allocation W is Walrasian in which renter $\mathbf{R} 3.1$ rents unit L1, and renter R2.1 rents unit L2. Reversing these two produces allocation Y, and this also produces the Walrasian surplus level of 2.2. A non-Walrasian allocation $\mathrm{X}$ is also feasible. Renter R3.1 might obtain the high-cost unit L3 paying a rent of 3.05. Renter $\mathbf{R 2 . 1}$ rents unit L2, and renter $\mathbf{R} 1.1$ rents unit L1, paying 2.05 and 1.05 respectively. The total surplus generated by this allocation is 0.3 .

Table A2: Possible Allocations

\begin{tabular}{|l|c|c|c|}
\hline & L1 & L2 & L3 \\
\hline R1.1 & X Z & & \\
\hline R2.1 & Y & X W Z & \\
\hline R3.1 & W & Y & X \\
\hline
\end{tabular}

In a world where agents search randomly to find rental units and conclude a bargain whenever the renter's reservation price exceeds that of the landlord, allocation $\mathrm{X}$ will occur approximately one third of the time, significantly reducing the expected total surplus realized from the market. Imposing a rent control on this market can increase total surplus. Suppose that rent control prohibits rents from being higher than 2.5. This eliminates the possibility of allocation $\mathrm{X}$, although it does raise the possibility of allocation Z (which would not arise without the rent control). Allocation Z provides total surplus of only 0.2, but (with random matching) occurs only one ninth of the time, so that expected surplus increases due to the rent control, although expected surplus does not rise to Walrasian levels. Guaranteeing maximal surplus is only possible by combining rent controls with some sort of price floor (which might be thought of as zoning or minimal standards regulations). 
This example illustrates another important aspect of rent control in non-Walrasian markets. Note that while imposing the rent control increases expected efficiency of the market, it exacerbates inequality in the distribution of surplus. Allocation X may have low total surplus, but it is certainly equitable, and does result in local accommodation being found for renter R1.1. Imposing rent control in this market increases total surplus but increases the variance in the surplus realized by the different agents. It makes it almost certain that renter R1.1 will not be accommodated in the market, and guarantees that the high marginal cost unit L3 will not be in residential use. Depending on the objective of the social planner, these outcomes may be regarded as too high a price to pay for the increase in total surplus. 
Notes

${ }^{1}$ In the sense of reducing the quantity and quality of housing available.

${ }^{2}$ The very fact that some renters in real-world markets are able to find what are widely regarded as "good deals” is indicative of the non-Walrasian character of those markets.

${ }^{3}$ Arnott and Igarashi provide an alternative reference point, but given that the primary focus of that paper is the impact of rent controls on welfare loss that results from the gap between the actual and ideal matching between consumers and the characteristics of the housing units they occupy in equilibrium, an issue that our model does not address, it is more useful to compare our findings to those of Glaeser and Luttmer. Gode and Sunder (1999) consider the general impact of non-binding price controls in a doubleauction market with zero-intelligence traders. A number of our findings have parallels in their results.

${ }^{4}$ Arnott (1995) makes the same point.

${ }^{5}$ More sophisticated models that incorporate heterogeneous search costs and/or queuing costs permit low reservation price consumers to get the price-constrained good in preference to consumers with higher prices, but in general these models assume that the good is rationed effectively on the basis of a more inclusive notion of price (Suen, 1989).

${ }^{6}$ Gode and Sunder (1999) refer to the costs of “displacement” of inframarginal traders by extramarginal traders.

${ }^{7}$ These differences could derive from differences in landlords' efficiency in providing maintenance of services or, alternatively, because owners of residential rental units near the central city might have greater returns in the commercial space market than those closer to the urban periphery.

${ }^{8}$ Because we assume all trades to occur, if at all, within the current market period, we do not apply any discount factor to trades that occur "later" within the market period, that is, subsequent to other trades.

${ }^{9}$ While it would be convenient perhaps to talk about simulating how a market "clears" or "reaches equilibrium,” these terms are problematical in a non-Walrasian context and so we avoid them. We will define the simulated “playing-out” of a market as a "market simulator run” or “market run.”) 
${ }^{10}$ In the terminology of auction-market theory, ours is a "continuous" rather than "synchronous" market process.

${ }^{11}$ Where "exhausting exchange possibilities" means there are no remaining pairings of buyer and seller that can result in positive expected surplus to at least one trader and non-negative expected surplus to both.

12 Introduced in Rubinstein (1982); also see Osborne and Rubinstein (1990)

13 To simplify exposition, we adopt the convention of using the feminine third-person pronoun in referring to renters and the masculine pronoun in referring to landlords.

${ }^{14}$ We assume that a single rental price ceiling, if any, applies to all rental units.

${ }^{15}$ This would be the rough equivalent of a renter (landlord) in a seasonal rental market, say a college town or summer resort, knowing the current date and also how well people in his situation fared in the past when they turned down deals on that date in hopes of a superior bargain. Note that our agents' information and foresight, though limited, are greater than that assumed for the zero-intelligence traders of Gode and Sunder (1997, 1999). Gode and Sunder (1997), however, derive an analytic solution. Simulation methods are employed in Gode and Sunder (1999).

16 This is the full information set of the agent; each agent has "experience-derived" knowledge of the benefit they can expect if they reject the trade.

${ }^{17}$ By equation (1), the proposed trade price would be the simple average of the reservation prices of the two parties to the exchange.

18 Tests indicate that the results are robust to changes in the bootstrap rejection rate.

${ }^{19}$ There are some agents whose reservation prices are such that they will have few opportunities for feasible bargains even with a bootstrap stage that includes 20,000 runs. Renters (landlords) with the very lowest (highest) reservation prices will never be able to conclude a bargain from which they receive surplus. In our model these agents’ expected gains will be zero at all transaction counts. 
${ }^{20}$ We experimented with extending this iterative process to include several more stages, but found that the market began to converge to the Walrasian market outcome within a relatively modest number of stages. This is in part a consequence of our assumptions of zero search costs and zero negotiation costs.

${ }^{21}$ It is worth noting that "large number effects" alone do not alter our results. That is, there is absolutely no qualitative difference in the outcome of a market in which there is one renter and one landlord at each integer price between 1 and 11, and a market in which there are 10,100, or 1000 renters and landlords at each integer price between 1 and 11. Similarly, there is no qualitative change in the results if there are 101 renters and landlords, each group distributed such that there was one agent of each type at each integer reservation price between 1 and 101. Clearly, changes in the relative slopes of the implicit supply and demand curves generated by the agents' reservation prices and their numbers will change the simulation results, an issue to which we return below.

${ }^{22}$ Of course, in which markets there may be an additional welfare cost due to excessive levels of search. ${ }^{23}$ Two points should be noted. First, while our model does not explicitly incorporate search costs, agents' behavior and the consequent market outcome is similar to an economy with search costs. In markets with search costs an agent deciding whether to reject a given bargain must weigh anticipated costs (of search) against the possible gains from finding a superior bargain, leading to acceptance of bargains that are not "best possible;" in our model as well, agents determine their bargaining position on the basis of the surplus they can expect to receive if they reject the trade. In both cases, the outcome is non-Walrasian. Second, unless there is a strong negative relation between agents' reservation price and their search costs (the opposite of what we would expect) the addition of search costs to our model would have the effect of lowering the net gain that agents could expect to obtain when rejecting a feasible trade at any given transaction count; this would have the effect of increasing the ability to trade of agents who would be extra-marginal in a Walrasian environment, thus increasing the size of the departure from the Walrasian outcome. 
${ }^{24}$ The simulation results that we present here and below should be viewed as average values over 20,000 “runs" of the market simulator with given values of agents' disagreement points. Thus a "total” value is an average total value and an "average" value is an average average value.

${ }^{25}$ The extent of extramarginal trading is not independent of the extent of agents' knowledge and strategic foresight. In our model, both are limited.

${ }^{26}$ The idea of effective "ineffective" price constraints is not novel, and has been verified in experimental settings. See for example Cottle and Wallace (1982). Note that the mechanism that drives their result is quite different from ours. Gode and Sunder's (1999) analysis of ineffective price controls deals explicitly with efficiency losses in non-Walrasian markets due to trading by extramarginal agents.

${ }^{27}$ A model by Fershtman and Fishman (1994) that analyses the effects of wage and price controls in (nonWalrasian) search markets finds that the direct price-lowering effect of a price ceiling can be outweighed by the indirect price-increasing effect of reduced search because the price ceiling reduces the benefit of search. Under some conditions in that model price ceilings can lead to higher average prices and wage floors to lower average wages.

${ }^{28}$ In effect, this is equivalent to a greater probability of being left standing after the music stops in a game of "musical chairs."

${ }^{29}$ Note that although the total surplus is lower when the price ceiling is 7 rather than 8, it is still higher at price ceiling 7 than when there is no price ceiling at all. Interestingly, total surplus is lower with a price ceiling of 6 than it is in the unconstrained case; this is because the supply-reduction effect of the price ceiling outweighs the impact of the elimination of some extramarginal landlords. Extramarginal trades by renters account for about one-sixth of all trades at a price ceiling of 6 .

${ }^{30}$ Gode and Sunder (1999) find similar results in double auction markets with zero-intelligence traders, suggesting that our results are not the consequence of our particular choice of agents' information sets or our bargaining model. 
${ }^{31}$ It is interesting to note that Smith (1776), speaking about interest rate controls, actually supported those that set the legal rate of interest “... but a very little above the lowest market rate....”, and asserted that such controls would have a beneficial impact on the economy. (Our thanks to Steve Meardon for pointing this out.)

32 "Mild rent controls" also increase total surplus in the model in Arnott and Igarashi (2000). In their model, the rent controls restrict landlords' ability to exercise monopoly power, leading to a welfare gain more akin to the gain from a price ceiling in a monopolistic market. Two recent papers by Michael Rauh (2001, 2002) also find that under some conditions a price ceiling can increase total welfare. In Rauh (2001) the welfare gains come strictly from reductions in search costs. In Rauh (2002) the price ceiling may or may not increase welfare because the reduction in search costs can be partially or fully offset by a shift of production to an inefficient producer; the net change in welfare in this paper by Rauh depends crucially on the relative inefficiency of the high-cost producer.

33 This assumption is certainly reasonable in a world where the income elasticity of demand for housing is approximately constant and equal to 1 . In such a world, if households spend about one third of their income on housing, the reservation price for each renter might be taken to be one third of household income.

${ }^{34}$ When compared to the unconstrained case.

${ }^{35}$ Renter 4 is affected, even though she could not herself successfully trade with landlord 7 , because the same number of renters is now competing to make trades with a smaller pool of landlords

${ }^{36}$ We have also performed non-Walrasian simulation exercises in which supply is more responsive to price changes than is demand. We do not discuss the results of those simulations in this paper; as standard Walrasian analyses would suggest, the tradeoffs between redistribution and total surplus are less favorable than in our base-case analysis.

${ }^{37}$ The average market price in our non-Walrasian environment, however, is not six.

${ }^{38}$ The comparable information for the base-case can be found in Table 5 above. 
${ }^{39}$ Recall that in the base-case a reduction in the price ceiling increases the probability that a landlord whose reservation price is below the ceiling will conclude a successful bargain while simultaneously reducing probability of any given renter doing so, thus partially offsetting the impact of the price ceiling on the agents' relative disagreement points in the Nash bargain; here there is no such offsetting force.

${ }^{40}$ We have experimented with modeling markets in which the supply is even more responsive to price changes than it is in our base-case simulations. As might be expected, imposition of price ceilings under such circumstances leads to large losses in total surplus. Further, because the supply effect of price ceilings is that much greater, low-reservation-price renters are much less likely to derive any benefit at all from them.

${ }^{41}$ The 'revisionist' view of rent controls identified in Arnott (1995), as well as other analyses that have suggested that rent controls might be beneficial when landlords have monopoly power (Arnott and Igarishi, 2001) or when search costs are significant relative to the level of rents (Fershtman and Fishman, 1994 and Rauh, 2001). Note that our results derive from the nature of the allocation process itself and do not rely on the presence of landlord market power or search costs that are significant relative to the rents themselves.

${ }^{42}$ While high-reservation-price renters gain from all but the lowest price ceilings, they suffer very large welfare losses at the lowest ceiling prices. High income voters might thus rationally vote against rent controls on the grounds that once rent controls are put in place, political forces will operate to push the ceilings down to those very low levels at which they suffer losses. 